\title{
¿ Global Climatologies of Fronts, Airmass Boundaries, and Airstream Boundaries: Why the Definition of "Front" Matters'
}

\author{
CARL M. THOMAS ${ }^{\mathrm{a}}$ \\ School of Physics and Astronomy, University of Manchester, Manchester, United Kingdom \\ DAVID M. SCHULTZ \\ Centre for Atmospheric Science, School of Earth and Environmental Sciences, University of \\ Manchester, Manchester, United Kingdom
}

(Manuscript received 18 August 2018, in final form 2 November 2018)

\begin{abstract}
Climatologies of fronts, airmass boundaries, and airstream boundaries can be calculated using automated approaches on gridded data. Such approaches may require choices to define a front, including a quantity (or quantities) to diagnose the front, a mathematical function(s) that operates upon the quantity to produce a diagnostic field, a level(s) at which the field is calculated, and a minimum threshold(s) in the magnitude of the field. To understand how resulting climatologies depend upon these choices using a consistent dataset, ERAInterim reanalyses from 1979 to 2016 are used to construct global monthly climatologies for various definitions of fronts and airstream boundaries from potential temperature, equivalent potential temperature, water vapor mixing ratio, and wind, including gradients, thermal front parameter, frontogenesis, and asymptotic contraction rate at the surface and $850 \mathrm{hPa}$. Maps of automated fronts are similar to manual analyses when about $10 \%$ of the map is identified as a front. Definitions of fronts that use potential temperature or frontogenesis produce climatologies similar to those of manually analyzed fronts with maxima along the major storm tracks and their seasonal migrations. In contrast, definitions that use equivalent potential temperature or the thermal front parameter produce fewer fronts at higher latitudes and more fronts at lower latitudes, more akin to airmass boundaries than fronts. Although surface fronts defined by thermodynamic quantities are more infrequent over the oceans than at $850 \mathrm{hPa}$, they are more frequent when using metrics that include the wind field (e.g., frontogenesis, asymptotic contraction rate).
\end{abstract}

\section{Introduction}

Constructing a spatial climatology of fronts based on a set of manually produced surface analyses can be tedious and time consuming. Indeed, only six studies constructed spatial climatologies of fronts from manual

¿ Denotes content that is immediately available upon publication as open access.

Supplemental information related to this paper is available at the Journals Online website: https://doi.org/10.1175/MWR-D-18-0289.s1.

\footnotetext{
${ }^{a}$ Current affiliation: Department of Physics, Imperial College London, London, United Kingdom.
}

Corresponding author: Prof. David M. Schultz, david.schultz@ manchester.ac.uk analyses in the 75 years between 1939 and 2014 (Table 1). Since the advent of global reanalysis datasets and powerful computers in the 1990 s, the ability to compute global climatologies of fronts has become much easier, proliferating the number of studies. In the 17 years since 2001, 12 studies, not including the present study, have been performed (Table 2). Such climatologies based on reanalysis datasets often use automated schemes originally created for use with gridded output from operational numerical weather prediction models to construct automated fronts (e.g., Hewson 1998; McCann and Whistler 2001; Santurette and Joly 2002; Hewson and Titley 2010).

Although these climatologies are created by automated schemes, humans must choose several key

This article is licensed under a Creative Commons Attribution 4.0 license (http://creativecommons. org/licenses/by/4.0/). 
TABLE 1. Climatologies of fronts and baroclinic zones based on manual synoptic analyses [adapted and updated from Table 1a in Thomas and Schultz (2019)].

\begin{tabular}{|c|c|c|c|c|}
\hline Reference & Location & Data source & Years & $\begin{array}{c}\text { Averaging } \\
\text { period }\end{array}$ \\
\hline Petterssen (1939) & $\begin{array}{l}\text { Eastern North Atlantic } \\
\text { and western Europe }\end{array}$ & Bergen synoptic maps & $1933-35$ & Jan \\
\hline $\begin{array}{l}\text { Schumann and van } \\
\text { Rooy (1951) }\end{array}$ & Northern Hemisphere & $\begin{array}{l}\text { U.S. Daily Historical } \\
\text { Weather Maps }\end{array}$ & $1928-38$ & DJF, JJA \\
\hline Reed and Kunkel (1960) & $20^{\circ}-90^{\circ} \mathrm{N}$ & $\begin{array}{l}\text { U.S. Weather Bureau Daily } \\
\text { Series Synoptic Weather } \\
\text { Maps }\end{array}$ & $1952-56$ & JJA \\
\hline Morgan et al. (1975) & $\begin{array}{l}\text { United States and } \\
\text { southern Canada }\end{array}$ & U.S. Daily Weather Maps & $1961-70$ & Monthly \\
\hline Flocas (1984) & Europe & $\begin{array}{l}\text { Daily synoptic charts from } \\
\text { three sources }\end{array}$ & $1971-79$ & Monthly \\
\hline Utsumi et al. (2014) & $\begin{array}{l}\text { Western Pacific around } \\
\text { Japan }\end{array}$ & $\begin{array}{l}\text { Asia Surface Analysis } \\
\text { Charts }\end{array}$ & $2000-10$ & Jan, Jul \\
\hline
\end{tabular}

characteristics to define a front with such schemes. Because inherently subjective decisions made by humans are required to create such schemes, we avoid the term "objective" to refer to such automated schemes [e.g., section 18.2 in Schultz (2009)]. Specifically, constructing a relatively simple automated frontal analysis typically requires five subjective (i.e., human made) choices in the definition of a front ${ }^{1}$ [description below adapted from Thomas and Schultz (2019)]:

1) A quantity-usually a thermodynamic quantity(or quantities) used to diagnose the front (e.g., potential temperature, equivalent potential temperature, wind).

2) A mathematical function(s) that operates upon the quantity to create the field for identifying the front (e.g., gradient, thermal front parameter, frontogenesis).

3) A level(s) or layer at which the analysis is performed (e.g., surface, $850 \mathrm{hPa}, 1 \mathrm{~km}$ above sea level, between 950 and $700 \mathrm{hPa}$ ).

4) A minimum threshold(s) or tolerance(s) in the magnitude of the field for the feature to be considered a front [e.g., magnitude of the horizontal gradient in potential temperature exceeding $\left.8 \mathrm{~K}(100 \mathrm{~km})^{-1}\right]$.

5) An algorithm to draw a line representing the front or to identify a region representing the frontal zone in the field at a given threshold and to classify the front as a warm or cold front, for example.

\footnotetext{
${ }^{1}$ Different methods for identifying fronts will identify different characteristics. For example, some diagnostics will identify contours that encircle a frontal zone in a horizontal plane, and others will identify the warm edge of the frontal zone (i.e., the front), as is consistent with synoptic practice. Still others will identify a frontal volume in three dimensions. For simplicity and internal consistency, and to be consistent with other authors, we simply refer to these identified features as fronts.
}

Although different methods are employed to create these automated climatologies and individual front cases have been compared using different techniques in the previous literature, a more comprehensive intercomparison is often not performed. Specifically, 8 of the 12 studies in Table 2 presented climatologies based on only one definition of a front. Intercomparison is essential because various approaches for defining fronts have strengths and weaknesses that affect the resulting climatologies (e.g., Hewson 1998; Jenkner et al. 2010; Berry et al. 2011b; Hope et al. 2014; Schemm et al. 2015, 2018; Thomas and Schultz 2019). Thus, one aim of this article is to evaluate how different definitions employed in the construction of automated frontal analyses may affect the resulting climatologies. We will present 17 of these frontal climatologies, some for the first time, using a consistent method and dataset. We will take a systematic approach to the study of the first three choices above (i.e., quantity, function, level) and provide some thoughts about the fourth choice, the minimum threshold. The fifth choice of the technique to draw the front is not explored in this article.

The second aim of this article is to show the annual cycles for these various definitions of fronts. Many of the studies in Table 2 do not present the annual cycle of the fronts; most just present annual or seasonal averages. Because the march of the seasons affects the storm tracks and hence the associated fronts, showing the annual cycle may avoid the smoothing inherent in annual or seasonal averages that may otherwise obscure potentially important differences between climatologies.

The remainder of this article is structured as follows. Section 2 presents the criteria for the quantities, functions, levels, and thresholds to be examined in this article. Section 3 presents the dataset and method used for computing the global climatologies. Section 4 presents 


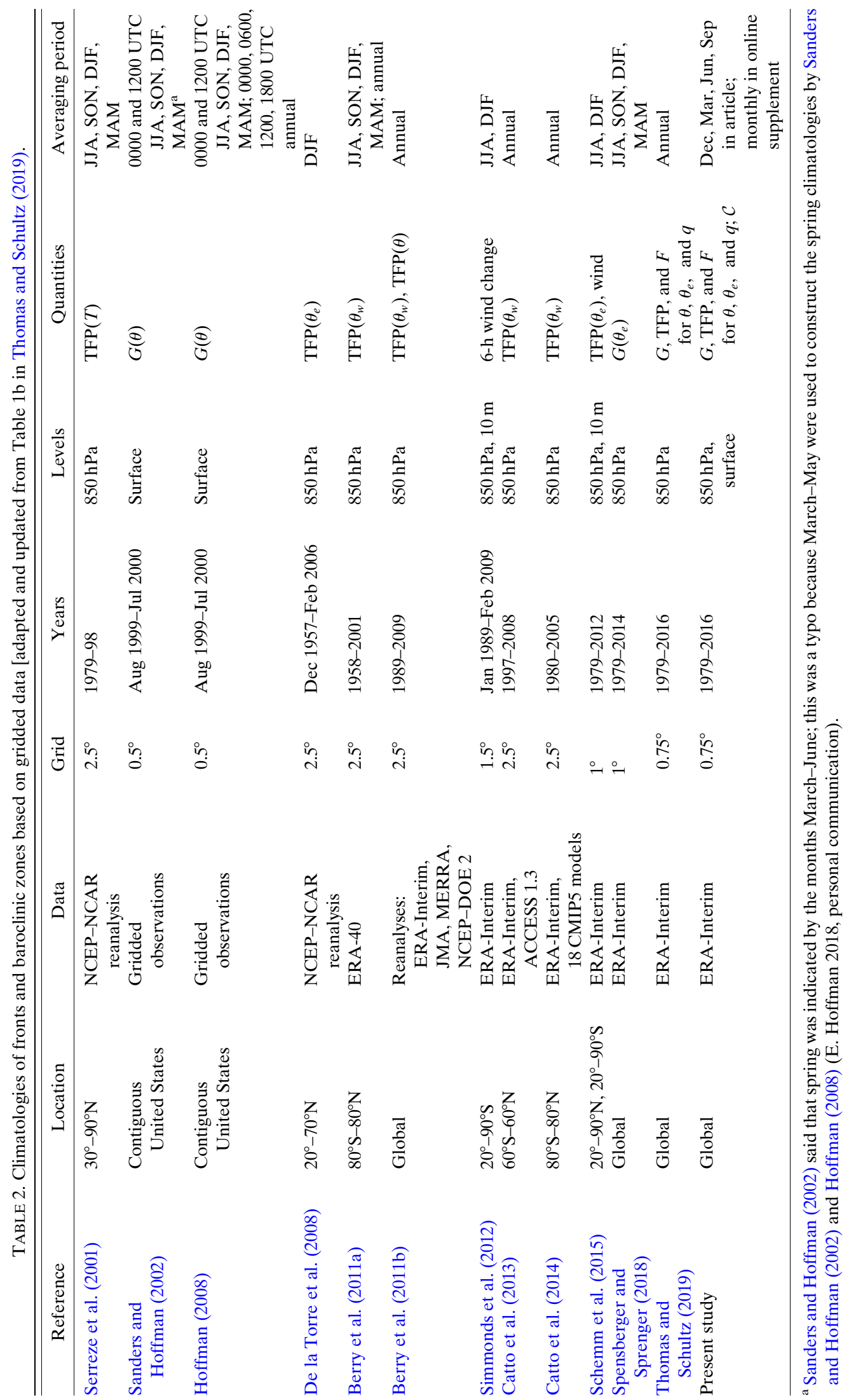


the global climatologies of fronts, airmass boundaries, and airstream boundaries from these various criteria at $850 \mathrm{hPa}$, whereas section 5 presents the climatologies at the surface. Section 6 discusses the definitions of fronts, airmass boundaries, and airstream boundaries as they relate to producing climatologies, and section 7 summarizes this article. An online supplemental file associated with this article contains animations of each of the monthly climatologies, providing a uniform atlas of these frontal quantities for the first time.

\section{Defining fronts, airmass boundaries, and airstream boundaries}

In this section, we explore the first four choices described in section 1: quantity, mathematical function, level, and minimum threshold.

\section{a. Quantity}

Fronts are defined as a density contrast between two air masses, and the dominant contribution to the density difference is the air temperature. Nearly all previous studies identify fronts by a thermodynamic quantity $\tau$ such as temperature $T$, potential temperature $\theta$, wetbulb potential temperature $\theta_{w}$, or equivalent potential temperature $\theta_{e}$ (Table 2). In this article, we use $\theta$ and $\theta_{e}$ for the reasons discussed below.

Potential temperature is favored over temperature as a diagnostic quantity because it accounts for adiabatic temperature changes due to pressure changes on any nonisobaric surface (e.g., surface of Earth, $1 \mathrm{~km}$ above the surface). Otherwise, potential temperature and temperature on a constant pressure surface have a oneto-one relationship, thus presenting equivalent information. To account for the density of water vapor in the air, Sanders (1999) suggested using virtual potential temperature $\theta_{v}$ instead of $\theta$, but climatologies we created using $\theta_{v}$ produced similar results to those using $\theta$ (not shown). As such, we stick to the more commonly used quantity $\theta$.

Both $\theta_{e}$ and $\theta_{w}$ are modified from $\theta$ to account for the release of latent heat due to the moisture content of an air parcel. Parcels with more moisture would have a larger adjustment to $\theta$ to obtain $\theta_{e}$ and $\theta_{w}$. Both $\theta_{e}$ and $\theta_{w}$ are not proportional to the density of the air, unlike $\theta_{v}$, yet both have been popular in climatologies (Table 2). Both $\theta_{e}$ and $\theta_{w}$ have a one-to-one relationship (Bindon 1940); thus, they present equivalent information. As such, we choose $\theta_{e}$, which is more commonly used by research groups in Europe and North America (e.g., Table 2).

Although the pros and cons of $\theta$ versus $\theta_{e}$ in defining fronts have been discussed elsewhere (e.g., Hewson
1998; Berry et al. 2011b; Schemm et al. 2018; Thomas and Schultz 2019), we do not continue that debate here. Instead, we focus on showing the implications of making this choice on the resulting climatologies.

Although some thermal quantity has been what most analysts have used to diagnose fronts (Table 2), two previous climatologies have used wind shifts to locate fronts (Simmonds et al. 2012; Schemm et al. 2015). Thus, the present study examines the wind field, as well.

\section{b. Mathematical function}

Following Hewson (1998, his Table 1), a variety of functions were considered to construct the monthly climatologies (Table 2). The strengths and weaknesses of some different mathematical functions to identify fronts are synthesized by Thomas and Schultz (2019). The functions considered in this article are described below.

First, we consider the simplest function that has been used to represent a frontal zone, the magnitude of the horizontal gradient operator $G$ :

$$
G(\tau)=|\nabla \tau|,
$$

where

$$
\nabla=\mathbf{i} \frac{\partial}{\partial x}+\mathbf{j} \frac{\partial}{\partial y}
$$

Forecasters often consider the magnitude of the horizontal temperature gradient in deciding whether to analyze a front or not. Not all temperature gradients are fronts, so some prefer to distinguish nonfrontal baroclinic zones from frontal zones (Sanders 1999, 2005; Sanders and Hoffman 2002). Nevertheless, the magnitude of the horizontal gradient has been used previously in constructing climatologies of fronts (Table 2). For example, Sanders (1999) considered moderate baroclinic zones to have gradients of the surface potential temperature of $4 \mathrm{~K}(110 \mathrm{~km})^{-1}$ and strong baroclinic zones to have gradients of $8 \mathrm{~K}(110 \mathrm{~km})^{-1}$. These values were used in the construction of climatologies of surface baroclinic zones by Sanders and Hoffman (2002) and Hoffman (2008).

Second, we consider the thermal front parameter (TFP) defined by Renard and Clarke (1965) and more recently popularized by Hewson (1998) as

$$
\operatorname{TFP}(\tau)=-\nabla|\nabla \tau| \cdot \frac{\nabla \tau}{|\nabla \tau|} .
$$

The thermal front parameter determines the edges of the baroclinic (or frontal) zone, and the negative sign ensures that the warm side of the baroclinic zone has a 
positive thermal front parameter [Fig. 3 in Hewson (1998)]. Thus, the thermal front parameter mimics the synoptic convention of drawing the front on the warm side of the baroclinic zone. The thermal front parameter has been popular in previous frontal climatologies: 8 out of the 12 studies in Table 2.

Third, we consider the horizontal frontogenesis function $F$, which is a kinematic quantity combining both a scalar quantity $\tau$ (usually a thermodynamic quantity) and the horizontal wind $\mathbf{V}=u \mathbf{i}+v \mathbf{j}$. The frontogenesis function has been employed in only one frontal climatology before: Thomas and Schultz (2019). Defined by Petterssen (1936),

$$
F(\tau)=\frac{d}{d t}|\nabla \tau|,
$$

where

$$
\frac{d}{d t}=\frac{\partial}{\partial t}+u \frac{\partial}{\partial x}+v \frac{\partial}{\partial y}
$$

The frontogenesis function [also called accumulation by Saucier (1955, p. 363)] represents the Lagrangian rate of change of the magnitude of the horizontal gradient of a scalar quantity $\tau$, such as $\theta, \theta_{e}$, or water vapor mixing ratio $q$. When $\tau=\theta$, the frontogenesis function is called Petterssen frontogenesis and is the Lagrangian rate of change of the magnitude of the horizontal gradient in potential temperature by the wind, which thus links to the physical processes by which fronts intensify (e.g., Keyser et al. 1988; Schultz 2015). This relationship was written by Petterssen (1936) more explicitly as

$$
F=\frac{1}{2}|\nabla \theta|(E \cos 2 \beta-\nabla \cdot \mathbf{V}),
$$

where $E$ is the resultant deformation, and $\beta$ is the local angle between an isentrope and the axis of dilatation measured in a counterclockwise direction. Deriving this equation requires the conservation of potential temperature, so diabatic effects are not explicitly included in (4).

When the wind is replaced by the geostrophic wind in (3), Petterssen frontogenesis by the geostrophic wind is related to the forcing for quasigeostrophic vertical velocity associated with the divergence of the component of the $\mathbf{Q}$ vector normal to the isentropes (e.g., Keyser et al. 1988), linking frontogenesis to the secondary circulation of the front. Thus, frontogenesis not only quantifies the kinematics of the intensification of a front, but also relates to the dynamics of the secondary circulation.
Because Petterssen frontogenesis is an instantaneous kinematic quantity, it cannot describe the long-term behavior of fronts, which comes from air parcels residing in a region of frontogenesis for a sufficient time. Thus, the fourth function we examine attempts to quantify this long-term behavior through a quantitative function called the asymptotic contraction rate $\mathcal{C}$ [Cohen and Schultz 2005, their Eq. (21b)]:

$$
\mathcal{C}=\frac{1}{2}\left[\left(E^{2}-\zeta^{2}\right)^{1 / 2}-\nabla \cdot \mathbf{V}\right]
$$

where $\zeta$ is the relative vorticity $(\nabla \times \mathbf{V})$. The asymptotic contraction rate $\mathcal{C}$ represents the long-term rate at which the distance between two adjacent air parcels decreases for a steady-state wind field that varies linearly in the horizontal. Because there is no thermodynamic variable in this function, asymptotic contraction rate is a function of the wind field only. As such, $\mathcal{C}$ can only be used to diagnose airstream boundaries, not fronts. Maxima in the asymptotic contraction rate can be used to locate regions where air parcels are coming together, thus providing a quantitative measure of an airstream boundary (Cohen and Kreitzberg 1997; Cohen and Schultz 2005). In that sense, the asymptotic contraction rate can complement Petterssen frontogenesis.

Two other functions have been suggested previously for computing fronts from wind fields. For identifying mobile fronts in the Southern Hemisphere, Simmonds et al. (2012) used the following criteria: 6-h veering wind change from the northwest quadrant to the southwest quadrant and the change in $v$ has to exceed $2 \mathrm{~m} \mathrm{~s}^{-1}$. A comparison between the Simmonds et al. (2012) method and TFP $\left(\theta_{e}\right)$ was performed by Schemm et al. (2015). They found that the Simmonds et al. (2012) method tends to detect meridionally elongated mobile fronts, but fails to identify zonally oriented warm fronts. We did not adopt this approach in the present study for this reason and because we wished to identify the front based on the fields at a single time, not as a difference field between two times.

Another frontal diagnostic was proposed by Solman and Orlanski (2010), who defined the front activity index as the product of the magnitude of the $850-\mathrm{hPa}$ horizontal temperature gradient and the magnitude of the $850-\mathrm{hPa}$ relative vorticity. This product is reminiscent of the Sanders $(1999,2005)$ criteria for a front, which require both a horizontal temperature gradient and a wind shift. However, the Solman and Orlanski (2010) quantity does not link this arbitrary mathematical product of two quantities to a physically relevant governing equation for fronts, unlike Petterssen frontogenesis, which is linked to the secondary circulation. Thus, the front 
activity index fails to meet the standards defined by Doswell and Schultz (2006) for a suitable forecasting parameter. Consequently, we do not adopt this approach in the present article. Thus, the magnitude of the horizontal gradient, thermal front parameter, frontogenesis, and asymptotic contraction rate are the four functions to be considered in the present article.

\section{c. Level}

Because fronts are strongest in the lower troposphere, and meteorological data for frontal analysis are most abundant at Earth's surface (strictly speaking, $10 \mathrm{~m}$ above ground level for wind data and $2 \mathrm{~m}$ above ground level for temperature and moisture data), previous studies have used the surface, $1 \mathrm{~km}$ above the surface, or $850 \mathrm{hPa}$. For all but two previous climatologies derived from gridded datasets (Table 2), the authors used $850 \mathrm{hPa}$ because the local heating effects and the weakening of the temperature gradient over the oceans by surface fluxes are less important above the boundary layer at $850 \mathrm{hPa}$. The debate over surface or aloft is discussed, for example, by Schemm et al. (2018, 151152). It is perhaps notable that Simmonds et al. (2012) was the only study to compare climatologies at both the surface and $850 \mathrm{hPa}$, and they used wind-based diagnostics. In the present study and for the first time in the published literature, we compare climatologies computed from thermodynamic quantities at both the surface and $850 \mathrm{hPa}$.

\section{d. Minimum threshold}

To identify a region on a map that may represent a front, a minimum value (or threshold) of the calculated diagnostic needs to be set. Once set, regions where the diagnostic exceeds this threshold can be identified as a front. Things to consider in determining this threshold include the following:

1) The area exceeding the threshold. For example, if the threshold is too low, then too many fronts would be identified relative to manual methods. On the other hand, if the threshold is too high, then too few fronts would be identified. At both extremes, the results could be unsatisfactory.

2) The resolution of the gridded data. For highresolution datasets and functions with a large number of spatial derivatives (e.g., TFP), computed diagnostics are likely to contain a lot of structure in the field with many bullseye of high values that make it difficult to identify coherent frontal features. Lower values of the threshold, different finite-differencing approaches, or smoothing of the field can improve the detection of fronts with such high-resolution data (e.g., Hewson 1998; Jenkner et al. 2010).

In the present study, maps of frontal diagnostics plotted using various thresholds and corresponding manually produced surface analyses were visually compared between the coauthors to produce maps that captured the relevant meteorological features, but not an excessive number of fronts. To illustrate our approach, Fig. 1 shows choices of four different thresholds for $850-\mathrm{hPa} G(\theta)$ for a time chosen at random over the North Atlantic Ocean and Europe. As the threshold is varied from 0.5 to 1.0 to 1.5 to $2.0 \mathrm{~K}(100 \mathrm{~km})^{-1}$, less area on the map is covered by shading, and regions considered fronts became better defined with fewer smaller areas of shading (Figs. 1a-d). In this case, the threshold of $2.0 \mathrm{~K}(100 \mathrm{~km})^{-1}$ most closely matches the operational surface analysis by the German weather service Deutscher Wetterdienst [cf. Fig. 1d and Fig. 2 of Thomas and Schultz (2019)], so this value is chosen as the threshold for 850-hPa $G(\theta)$.

One metric that can be used to characterize the sensitivity of the selection of the threshold is the percentage of the map exceeding a certain threshold. To obtain this metric, the global distribution of the quantity was calculated for four times, one from each season. These four distributions were averaged together to produce a cumulative frequency distribution that served as our estimate of the fraction of points exceeding a given threshold. These times were 0000 UTC on these four dates: 1 March, 1 June, 1 September, and 1 December 2016. These cumulative frequency distributions were calculated for all quantities used in this study. As an illustration of one of these distributions, the cumulative frequency distribution of $850-\mathrm{hPa} G(\theta)$ for all global grid points is presented in Fig. 2. The curve is labeled with the value of this curve for the thresholds in Figs. 1a-d. For example, the fraction for the threshold of $2.0 \mathrm{~K}(100 \mathrm{~km})^{-1}$ was 0.131 , meaning that $13.1 \%$ points had a higher value than the threshold. Interestingly, contoured fields for diagnostics at $850 \mathrm{hPa}$ that cover $9 \%-13 \%$ of the map with frontal zones most closely match hand-analyzed surface maps. Based on these results for $850 \mathrm{hPa}$, when selecting thresholds for quantities calculated at the surface, we chose thresholds that captured roughly the upper $10 \%$ of the distribution (Table 3).

\section{Data and method}

The dataset to create the climatologies was the European Centre for Medium-Range Weather Forecasts (ECMWF) interim reanalysis (ERA-Interim; 

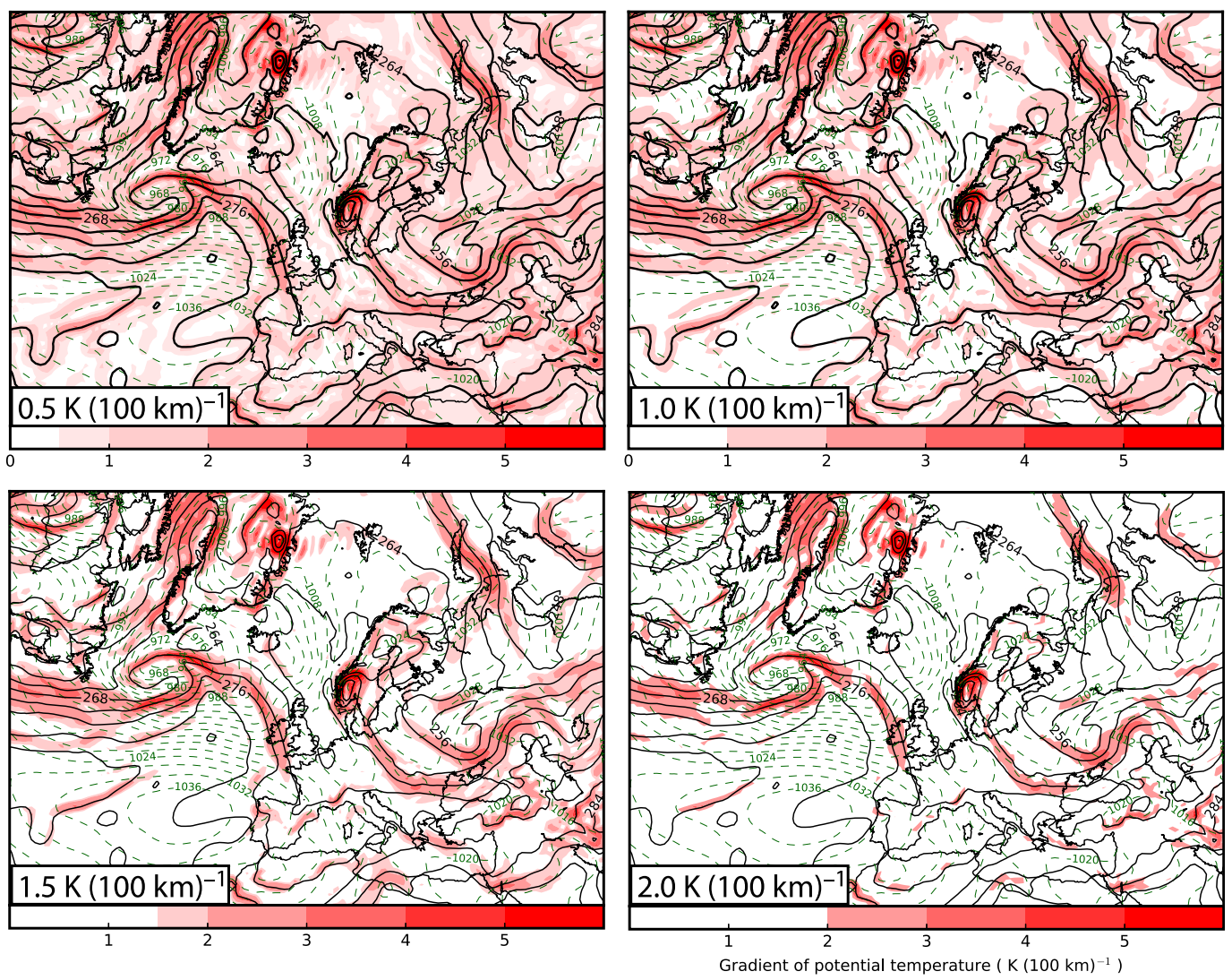

FIG. 1. Varying the threshold for $850-\mathrm{hPa} G(\theta)$ (colored according to scale) for 0000 UTC 24 Jan 2014 from (a) 0.5 , (b) 1.0 , (c) 1.5 , and (d) $2.0 \mathrm{~K}(100 \mathrm{~km})^{-1}$. Solid lines are $850-\mathrm{hPa}$ potential temperature (every $3 \mathrm{~K}$ ), and dashed green lines are sea level pressure (every $4 \mathrm{hPa}$ ).

Dee et al. 2011). Fields were obtained at 6-h intervals during 1979-2016 at both $850 \mathrm{hPa}$ and the surface (10-m winds, 2-m temperature, and 2-m water vapor mixing ratio). Fields were downloaded from ECMWF onto a latitude-longitude grid spacing of $0.75^{\circ} \times 0.75^{\circ}$.

The climatologies in this present article were constructed by counting the number of times at each grid point at each 6-h time the given frontal diagnostic exceeded the stated threshold in Table 3. These numbers of times were then divided by the number of $6-\mathrm{h}$ intervals per month over the whole data period (19792016) to obtain a percentage of time during each month where the threshold was exceeded (Figs. 3-4, 6-8, and 10-23). In the figures in the present article, these quantities are presented one month per season: December, March, June, and September. Annual cycles of these climatologies constructed from all 12 months are found in the online supplemental material.

\section{Climatologies at $850 \mathrm{hPa}$}

The climatologies in this section are presented at $850 \mathrm{hPa}$ and are organized by mathematical function, where section 4a presents the climatologies produced by the gradient function, section $4 \mathrm{~b}$ presents the climatologies produced by the thermal front parameter, section $4 \mathrm{c}$ presents the climatologies produced by the

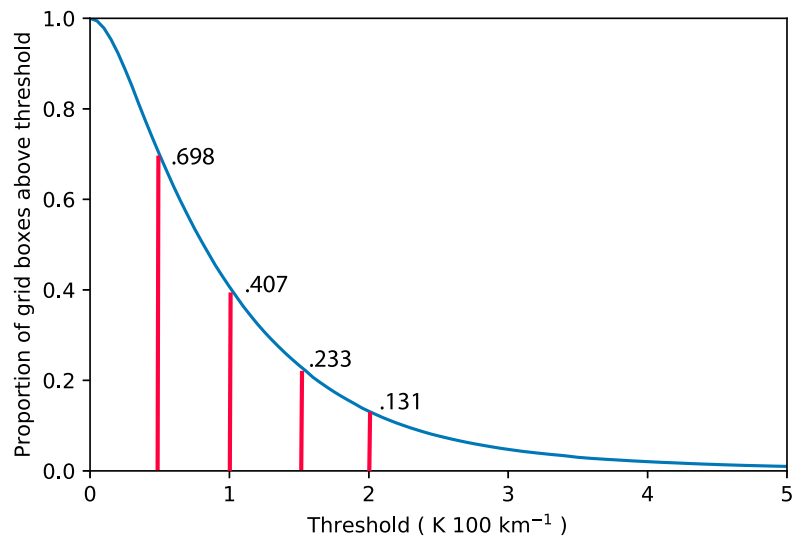

FIG. 2. Cumulative frequency distribution of $850-\mathrm{hPa} G(\theta)$ on all grid points at 0000 UTC on these four dates: 1 Mar, 1 Jun, 1 Sep, and 1 Dec 2016. Red lines are associated with the thresholds used in Figs. 1a-d, labeled with the value of the curve. 
TABLE 3. Diagnostic quantities used in the present study, their units, and thresholds and percentiles at $850 \mathrm{hPa}$ and the surface.

\begin{tabular}{|c|c|c|c|c|c|}
\hline \multirow[b]{2}{*}{ Quantity } & \multirow[b]{2}{*}{ Units } & \multicolumn{2}{|c|}{$850 \mathrm{hPa}$} & \multicolumn{2}{|c|}{ Surface } \\
\hline & & Threshold & Percentile & Threshold & Percentile \\
\hline$G(\theta)$ & $\mathrm{K}(100 \mathrm{~km})^{-1}$ & 2 & 13.1 & 3.3 & 9.9 \\
\hline$G\left(\theta_{e}\right)$ & $\mathrm{K}(100 \mathrm{~km})^{-1}$ & 4 & 12.6 & 6.2 & 9.9 \\
\hline$G(q)$ & $\mathrm{g} \mathrm{kg}^{-1}(100 \mathrm{~km})^{-1}$ & 2 & 7.0 & & \\
\hline $\operatorname{TFP}(\theta)$ & $\mathrm{K}(100 \mathrm{~km})^{-2}$ & 1 & 9.1 & 1.35 & 9.9 \\
\hline $\operatorname{TFP}\left(\theta_{e}\right)$ & $\mathrm{K}(100 \mathrm{~km})^{-2}$ & 2 & 9.4 & 2.8 & 10.0 \\
\hline $\operatorname{TFP}(q)$ & $\mathrm{g} \mathrm{kg}^{-1}(100 \mathrm{~km})^{-2}$ & 0.5 & 17.4 & & \\
\hline$F(\theta)$ & $\mathrm{K}(100 \mathrm{~km})^{-1} 3 \mathrm{~h}^{-1}$ & 0.3 & 9.1 & 0.275 & 9.8 \\
\hline$F\left(\theta_{e}\right)$ & $\mathrm{K}(100 \mathrm{~km})^{-1} 3 \mathrm{~h}^{-1}$ & 0.5 & 10.3 & 0.055 & 9.8 \\
\hline$F(q)$ & $\mathrm{g} \mathrm{kg}^{-1}(100 \mathrm{~km})^{-1} 3 \mathrm{~h}^{-1}$ & 0.1 & 15.0 & & \\
\hline $\mathcal{C}$ & $\mathrm{s}^{-1}$ & 0.3 & 10.2 & 0.275 & 10.2 \\
\hline$F(\theta)<0$ & $\mathrm{~K}(100 \mathrm{~km})^{-1} 3 \mathrm{~h}^{-1}$ & -0.15 & 9.4 & -0.18 & 10.0 \\
\hline
\end{tabular}

frontogenesis function, and section $4 \mathrm{~d}$ presents the climatology produced by the asymptotic contraction rate.

\section{a. Gradient}

Of all published climatologies of fronts from gridded data (Table 2), no other study has presented a climatology of the magnitude of the horizontal gradient of potential temperature at $850 \mathrm{hPa}$, except Thomas and Schultz (2019). The climatology of regions where $850-\mathrm{hPa} G(\theta)$ exceeds the threshold of $2 \mathrm{~K}(100 \mathrm{~km})^{-1}$ shows broad regions greater than $5 \%-10 \%$ frequency in the mid- and high latitudes (Fig. 3). In contrast to these maxima, regions exceeding the threshold over the subtropical and tropical oceans occur less than $1 \%$ of the time, if at all. Within the midlatitudes, prominent maxima are associated with cyclones in the storm tracks over the North Pacific and Atlantic Oceans. In the Southern Hemisphere, a large maximum coincident with the storm track extends from the South Atlantic and across the Indian Ocean. Over the South Atlantic, maxima in $G(\theta)$ coincide with the SST gradients associated with the oceanic subtropical convergence (e.g., Burls and Reason 2006). Maxima off the west coasts of continents (North and South America, Africa, Australia) are associated with thermal gradients in the atmosphere associated with upwelling of cooler water in

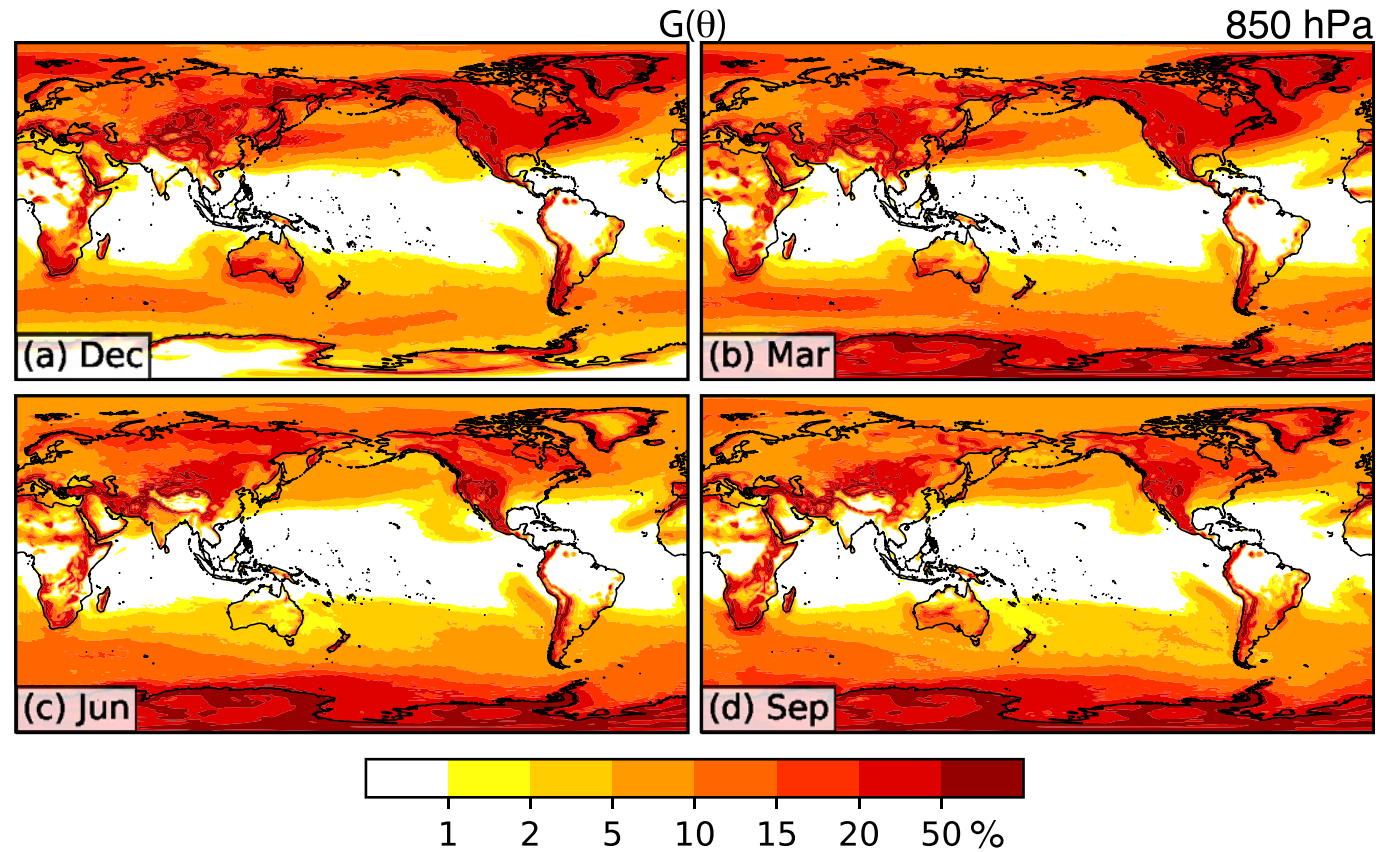

FIG. 3. Frequency of $850-\mathrm{hPa} G(\theta)$ exceeding $2 \mathrm{~K}(100 \mathrm{~km})^{-1}$ (\%; colored according to scale) for (a) December, (b) March, (c) June, and (d) September. 


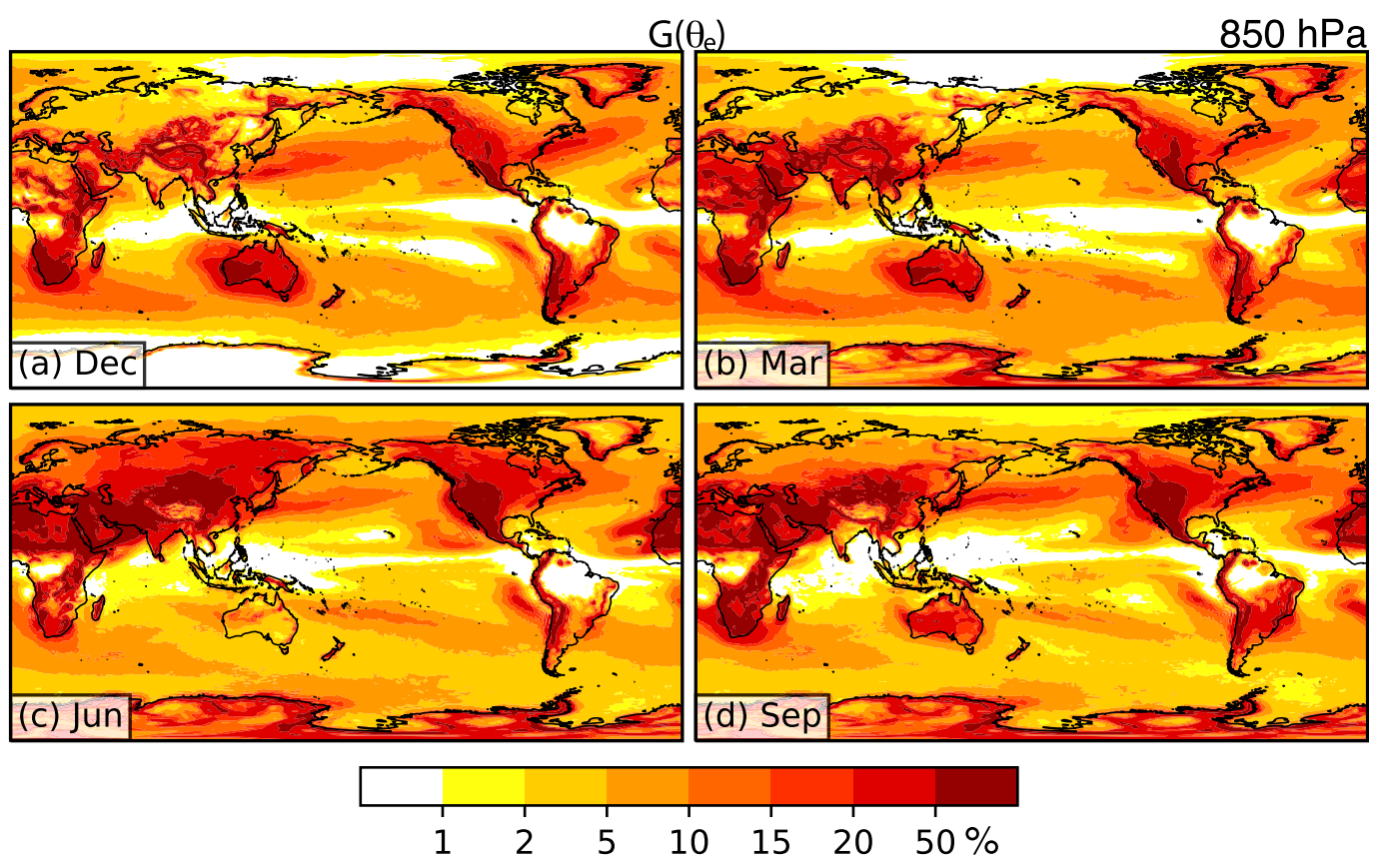

FIG. 4. Frequency of $850-\mathrm{hPa} G\left(\theta_{e}\right)$ exceeding $4 \mathrm{~K}(100 \mathrm{~km})^{-1}$ (\%; colored according to scale) for (a) December, (b) March, (c) June, and (d) September.

the eastern ocean basins. Maxima along and in the lee of the Rocky Mountains occur throughout the year, especially along the Front Range of Colorado where frequencies exceed $50 \%$ (Figs. 3a,b). High frequencies are also found near other mountain ranges (e.g., Andes, East Africa, Greenland, Antarctica, Tibetan Plateau, Himalayas, Madagascar, New Guinea Highlands). In part, these regions are a consequence of the $850-\mathrm{hPa}$ level intersecting the surface, with accompanying strong gradients in temperature. Thus, caution should be used when assessing these fields near terrain.

The seasonal variation in the Northern Hemisphere is more pronounced than in the Southern Hemisphere (Fig. 3). The regions of frequent gradients in potential temperature associated with the storm tracks in the Northern Hemisphere strengthen and shift equatorward during December and March, compared to June and September (cf. Figs. 3a,b and Figs. 3c,d). Fronts occur more than $20 \%$ of the time over most of North America during December and March (Figs. 3a,b), in contrast to a relative minimum over southern and south-central North America during June and September (Figs. 3c,d). In the Southern Hemisphere, the locations of highest frequency associated with the storm tracks appear to be best defined (i.e., stronger and better separated from year-round higher frequencies around Antarctica) in December and March, compared to June and September (cf. Figs. 3a,b and Figs. 3c,d).
Previous climatologies of manually analyzed surface fronts (Table 1) show many of the same features as in this climatology. Schumann and van Rooy (1951, their Figs. 2 and 3) highlighted the storm-track regions across both ocean basins in summer and winter, aligning well with our climatology. Reed and Kunkel (1960, their Fig. 6) also showed maxima coincident with the two oceanic storm tracks, but also showed a maximum in summertime lee cyclogenesis in the central United States that matches up well with that in Fig. 3c. Their region coincident with the summer storm track across Europe, however, does not appear to be more sharply defined, compared with our Fig. 3c. Morgan et al. (1975) showed a poleward shift in different types of fronts in the central and eastern United States in the warmer months and relative maxima along the west coast associated with upwelling (best seen in June and September in Figs. 3c,d), consistent with our results. The schematic graphics of winter and summer "principal frontal zones" by Petterssen (1956, his Figs. 11.11.1 and 11.11.2) capture some similarities (e.g., frontal zones associated with the storm tracks across the Pacific, Atlantic, and Mediterranean in winter), but also some differences (e.g., Petterssen's two maxima for the winter Pacific polar front are not replicated in Fig. 3a). Flocas (1984) showed a broad maximum in fronts northeast of Italy, whereas our study showed a much smaller maximum northwest of Italy (Fig. 3). In contrast, Hoffman (2008) showed much 

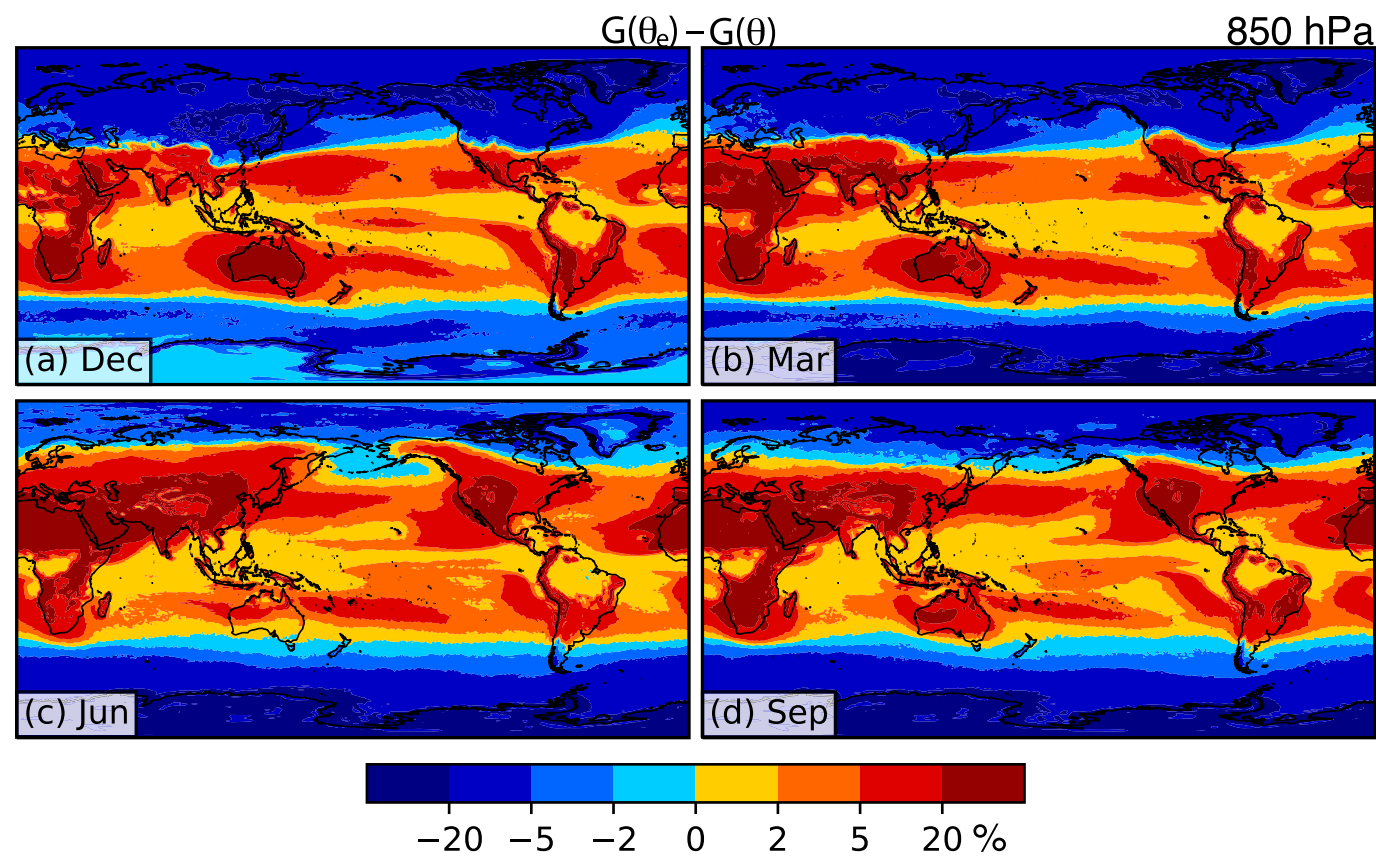

FIG. 5. Difference between the frequencies of $G\left(\theta_{e}\right)$ in Fig. 3 and $G(\theta)$ in Fig. 4 at $850 \mathrm{hPa}$ (\%; colored according to scale) for (a) December, (b) March, (c) June, and (d) September.

finescale detail around the coasts not replicated in our climatology, and Utsumi et al. (2014) showed seasonal behavior in the mei-yu front that does not appear to be captured in our climatology. These poor comparisons suggest that these shallower surface fronts associated with near-surface temperature gradients are not well replicated in this coarser analysis based on $850-\mathrm{hPa}$ ECMWF reanalyses.

Next, we examine the climatology of $G\left(\theta_{e}\right)$ (Fig. 4). Table 2 shows that only one climatology based on $G\left(\theta_{e}\right)$ has been produced: Spensberger and Sprenger (2018, their Fig. 2). Because horizontal gradients of $\theta$ are generally weaker than horizontal gradients in $\theta_{e}$, a higher threshold is applied: $2 \mathrm{~K}(100 \mathrm{~km})^{-1}$ for $G(\theta)$ versus $4 \mathrm{~K}(100 \mathrm{~km})^{-1}$ for $G\left(\theta_{e}\right)$ (Table 3$)$. The factor of 2 difference is consistent with Thorpe and Clough (1991, 921-923) who showed that gradients of $\theta_{e}$ across wintertime North Atlantic fronts are attributed to roughly equal gradients in humidity and temperature. Because $\theta_{e}$ is a function of both temperature and moisture, differences between gradients in $\theta$ and $\theta_{e}$ will be due to moisture. Indeed, the climatology of $G\left(\theta_{e}\right)$ shows many similarities to that of $G(\theta)$, but with the following differences (cf. Figs. 3 and 4):

1) Maxima in $G\left(\theta_{e}\right)$ occur in the subtropics and over the oceans, regions where moisture gradients are larger, compared to the mid- and high latitudes and over land in $G(\theta)$.
2) Regions of $G\left(\theta_{e}\right)$ that are coincident with storm tracks are farther equatorward where moisture is larger, especially in December and June.

3) The South Atlantic and South Pacific convergence zones (e.g., Vincent 1994; Folland et al. 2002; Carvalho et al. 2004; Charles et al. 2014) are more prominent in the $G\left(\theta_{e}\right)$ climatology.

4) A stronger and persistent maximum off the west coast of South America extends around the equatorward flank of the South Pacific anticyclone (Garreaud et al. 2002). A similar feature occurs off the west coast of Mexico on the equatorward flank of the North Pacific anticyclone in the $G\left(\theta_{e}\right)$ climatology.

5) A much greater seasonal contrast occurs in southern Asia, Africa, and the west coast of North America in the $G\left(\theta_{e}\right)$ climatology than in the $G(\theta)$ climatology.

6) A much stronger seasonal cycle in $G\left(\theta_{e}\right)$ exists across Australia than in $G(\theta)$.

Quantitatively, the differences between the climatologies of $G\left(\theta_{e}\right)$ and $G(\theta)$ can be illustrated by plots of $G\left(\theta_{e}\right)-G(\theta)$ (Fig. 5). Although the magnitude of the values on these plots would differ depending on the selected thresholds (e.g., Hewson and Titley 2010; Jenkner et al. 2010), the qualitative patterns of the plot would be similar regardless of the thresholds. Figure 5 reveals the following results: 


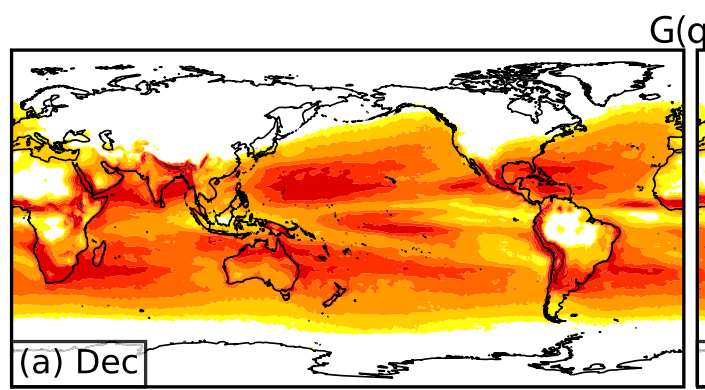

$\mathrm{G}(\mathrm{q})$ $850 \mathrm{hPa}$
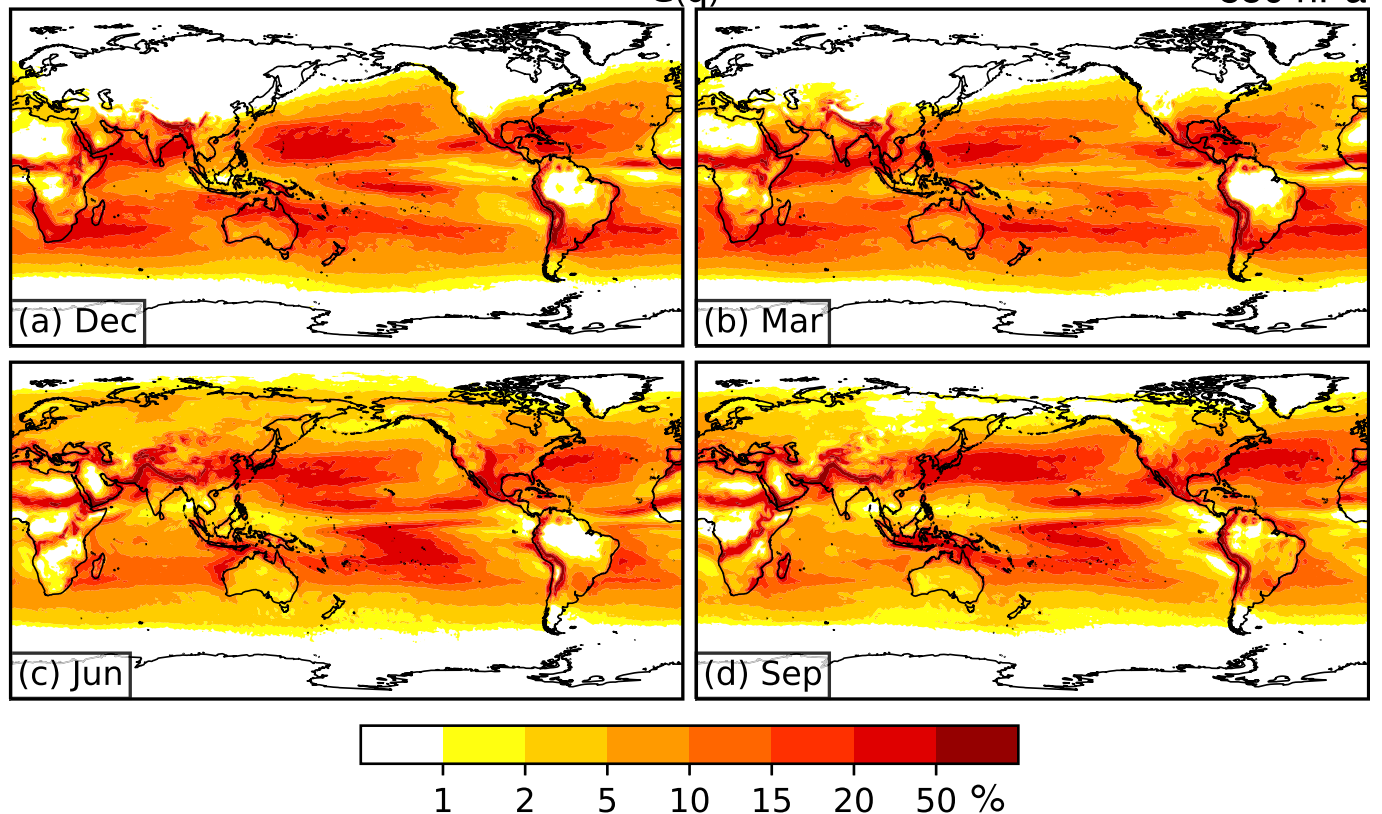

FIG. 6. Frequency of $850-\mathrm{hPa} G(q)$ exceeding $2 \mathrm{~g} \mathrm{~kg}^{-1}(100 \mathrm{~km})^{-1}$ (\%; colored according to scale) for (a) December, (b) March, (c) June, and (d) September.

1) Regions in the tropics and subtropics more frequently exceed the $G\left(\theta_{e}\right)$ threshold, compared to regions in the mid- and high latitudes that more frequently exceed the $G(\theta)$ threshold.

2) A dipole of maximum/minimum $G\left(\theta_{e}\right)-G(\theta)$ occurs along the storm tracks indicating the more equatorward location of the storm tracks in $G\left(\theta_{e}\right)$ than in $G(\theta)$.

3) In the summer and autumn hemispheres, higher latitudes have a more frequent occurrence of $G\left(\theta_{e}\right)$ compared to $G(\theta)$, a pattern that is notably strong over Canada and Alaska in June, compared to December (cf. Figs. 5a,c), perhaps associated with vegetation and evapotranspiration effects.

These differences can be explained by moisture being included in $\theta_{e}$. To illustrate the effect of the moisture in another way, we create a climatology of $G(q)$, which shows that frequent regions of $G\left(\theta_{e}\right)$ that were not also observed in the climatology of $G(\theta)$ could be explained by moisture gradients (cf. Figs. 6, 3, and 4). Specifically, the frequency of $G(q)$ exceeding the threshold tends to be larger in the tropics and the subtropics, compared to higher latitudes (Fig. 6), which leads to gradients in $\theta_{e}$ more frequent than gradients in $\theta$ at lower latitudes (cf. Figs. 3 and 4). The regions of gradients in moisture shift to higher latitudes in the summer hemispheres, with frequent occurrence of strong gradients along the northern coastline of Europe and Asia in June, for example (Fig. 6c).
Other features in the climatology of $G(q)$ include moisture gradients in the Pacific existing on either side of the intertropical convergence zone (ITCZ) and the seasonal shifts of the ITCZ bearing some similarity to some features in the seasonal shifts in the moisture gradients (e.g., Waliser and Gautier 1993). For example, a humidity gradient from the Horn of Africa to Southeast Asia is prominent in March (Fig. 6b), but weakens and shifts north in the boreal summer over southern Asia (Figs. 6c,d), corresponding to a movement in the ITCZ (e.g., Schneider et al. 2014). In another example, a maximum in moisture gradient occurs across northern Australia and extends into the South Pacific (Figs. 6a,b). This region appears to be coincident with the South Pacific convergence zone [e.g., Fig. 1 in Folland et al. (2002); Fig. 2 in Charles et al. (2014)].

Another climatological feature prominent in the $G\left(\theta_{e}\right)$ and $G(q)$ climatologies is the Intertropical Front, the airmass boundary separating the northeasterly hot, dry harmattan wind from the West African monsoon. The annual movement of the Intertropical Front can be seen as the moisture gradient across central Africa advances northward into the Sahel in March and June (Figs. 6b,c) and recedes in September and December (Figs. 6d,a; e.g., Lélé and Lamb 2010).

\section{b. Thermal front parameter}

The climatology for $\operatorname{TFP}(\theta)$ in Fig. 7 shows many of the same features as the climatology of $G(\theta)$ in Fig. 3, 

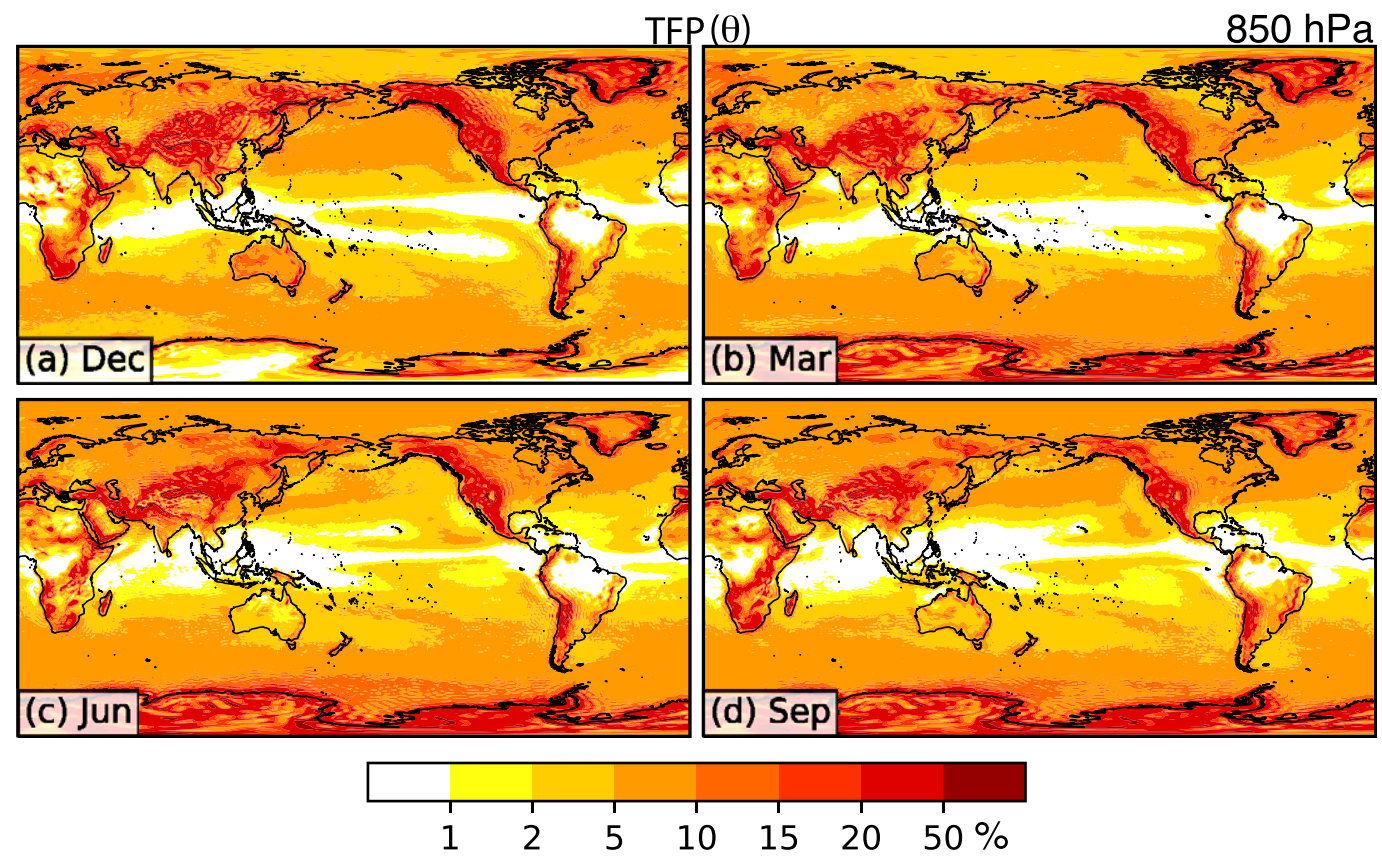

FIG. 7. Frequency of $850-\mathrm{hPa} \operatorname{TFP}(\theta)$ exceeding $1 \mathrm{~K}(100 \mathrm{~km})^{-2}$ (\%; colored according to scale) for (a) December,

(b) March, (c) June, and (d) September.

including the maxima along the oceanic storm tracks in both hemispheres. In addition, the regions with the highest frequency of $\operatorname{TFP}(\theta)$ exceeding the threshold are found close to mountain ranges in Africa, southwest Asia, and western North America (Fig. 7). There are higher frequencies and more structure in the $\operatorname{TFP}(\theta)$ field at lower latitudes, compared to the $G(\theta)$ field, especially over the tropical eastern Pacific Ocean and Indian Ocean (cf. Figs. 3 and 7). These higher frequencies and more structure in the field when compared to $G(\theta)$ are a result of the higher number of derivatives in the TFP function in (2) acting on the weaker and more variable horizontal temperature gradients in the tropics, as well as the detection of $\operatorname{TFP}(\theta)$ on the warm side of the baroclinic zone.

Only two of the climatologies in Table 2 used TFP of air temperature or potential temperature to produce climatologies [i.e., Fig. 4 in Serreze et al. (2001); Fig. 4b in Berry et al. (2011b)]. Their results are mostly similar to those in Fig. 7, showing the broad features such as those coincident with the storm tracks, but also more subtle features such as relative maxima southeast of Greenland, west of Mexico, off the northwest coast of North America, and across the north Mediterranean coast.

The climatology of $\operatorname{TFP}\left(\theta_{e}\right)$ in Fig. 8 shows an even more dramatic departure from $G\left(\theta_{e}\right)$ than $\operatorname{TFP}(\theta)$ was from $G(\theta)$. Almost all of the globe at all seasons (except the highest latitudes and some places near the equator) experiences thresholds being exceeded at least $5 \%$ of the time (Figs. 8a-d), suggesting more global, more frequent, and more variable distribution of fronts determined by this metric, compared to manual frontal analyses from the studies in Table 1, as well as other metrics [e.g., $G(\theta)]$. There is more structure in the field at lower latitudes and much higher percentages in $\operatorname{TFP}\left(\theta_{e}\right)$, compared to $G\left(\theta_{e}\right)$. The regions associated with the storm tracks in all seasons are less well defined and do not extend as far across the ocean basins as is the case for $G\left(\theta_{e}\right)$ or even TFP $(\theta)$ (cf. Figs. 8, 4, and 7).

Seven climatologies in Table 2 have used $\operatorname{TFP}\left(\theta_{e}\right)$ or $\operatorname{TFP}\left(\theta_{w}\right)$, resulting in the most popular diagnostic for fronts in the previous literature. Key results from comparing the monthly climatologies in Fig. 8 with these previous studies include the following:

1) De la Torre et al. (2008, their Fig. 3) calculated the number of times the $\operatorname{TFP}\left(\theta_{e}\right)$ exceeded $2 \mathrm{Km}^{-2}$, which is ten orders of magnitude higher than our threshold of $2 \mathrm{~K}(100 \mathrm{~km})^{-2}$. (This value would appear to be a typo in their paper.) Despite this difference, the spatial distribution matches well with our climatology (e.g., the region associated with the storm track off the east coast of North America, maximum across southern Europe, higher values west of southern North America), except in regions of high terrain where they have minima as opposed to our maxima (e.g., Greenland, western North America).

2) Compared to the annual averages presented by Berry et al. (2011a, their Fig. 2d), Catto et al. (2013, 


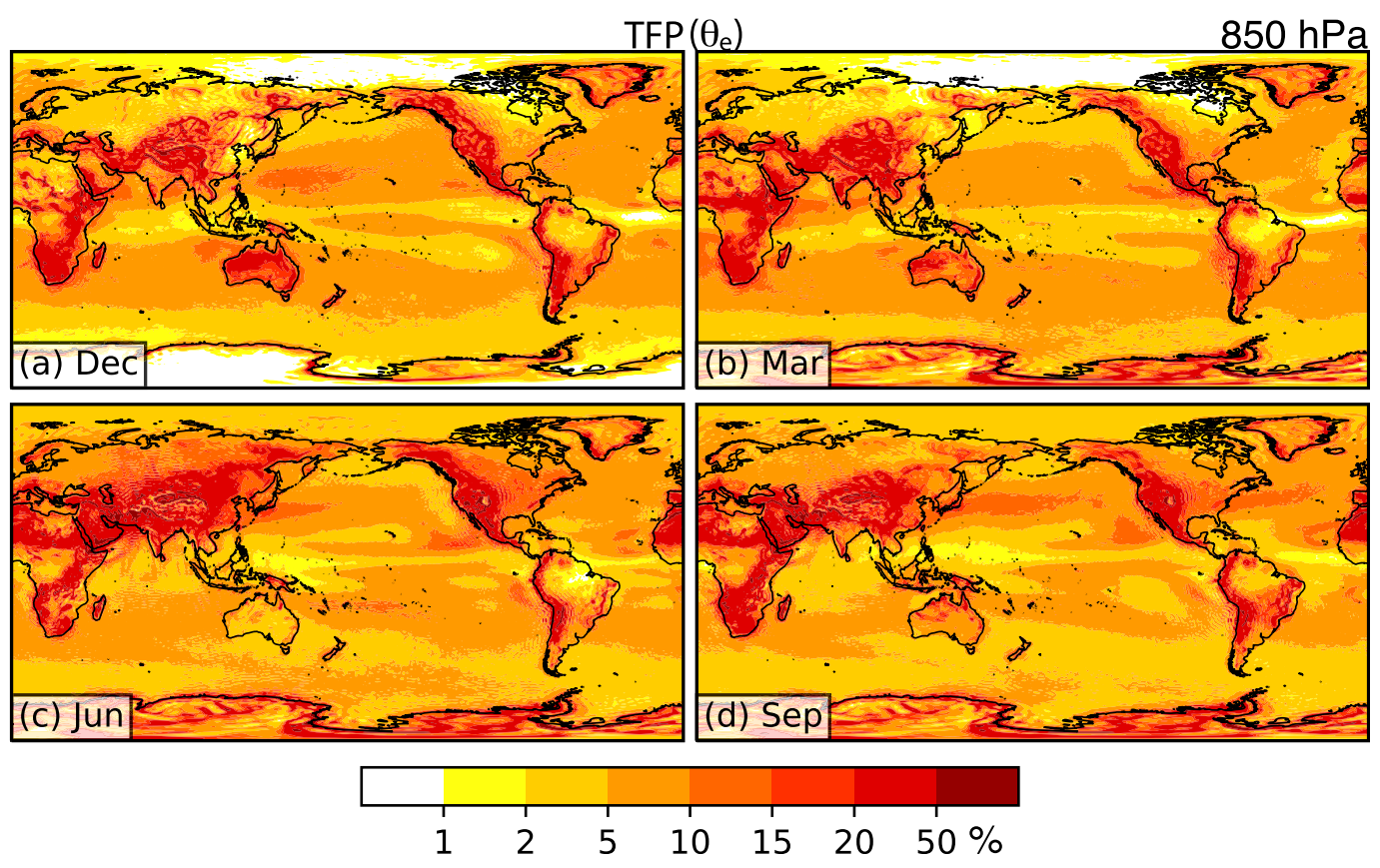

FIG. 8. Frequency of $850-\mathrm{hPa} \operatorname{TFP}\left(\theta_{e}\right)$ exceeding $2 \mathrm{~K}(100 \mathrm{~km})^{-2}$ (\%; colored according to scale) for (a) December,

(b) March, (c) June, and (d) September.

their Fig. 2a), and Catto et al. (2014, their Fig. 1a), most of the synoptic-scale features in our Fig. 8 and Thomas and Schultz (2019, their Fig. 7b) are quite similar. (Regions of high terrain are blocked out in the figures in those three studies, however.)

3) Interestingly, the annual average across four different reanalyses used by Berry et al. (2011b, their Figs. 4a,b) shows much less difference between $\operatorname{TFP}(\theta)$ and $\operatorname{TFP}\left(\theta_{e}\right)$ than for our climatologies (cf. Figs. 7 and 8), which suggests that the averaging process across both months and reanalyses smooths out any differences. This reduces the field to the large-scale and most common features, thereby making their Figs. 4a and $4 \mathrm{~b}$ appear similar to each other; see also the smoother annual average in Thomas and Schultz (2019, their Figs. 6b and 7b).

4) In contrast, the regions associated with the storm tracks in each hemisphere dominate the climatology presented by Schemm et al. (2015, their Figs. 5a,c and $6 \mathrm{a}, \mathrm{c})$, which does not extend equatorward of $20^{\circ} \mathrm{N}$ and $20^{\circ} \mathrm{S}$ latitude, and therefore cuts off the regions of high $\operatorname{TFP}\left(\theta_{e}\right)$ in Fig. 8 that were not the focus of their study (their p. 1696).

5) There is a rough relationship between the features identified by the $\operatorname{TFP}\left(\theta_{e}\right)$ climatology in Fig. 8 and the airstream regions defined by Wendland and Bryson (1981, their Fig. 10) for the Northern Hemisphere and by Wendland and McDonald (1986, their Fig. 9) for the Southern Hemisphere, particularly those in low latitudes. Thus, $\operatorname{TFP}\left(\theta_{e}\right)$ may not only represent fronts in the midlatitudes, but may also represent airmass boundaries from the subtropics that are largely a result of humidity gradients.

As with the gradient function in section 4a and Fig. 5, the quantitative differences between the climatologies of $\operatorname{TFP}\left(\theta_{e}\right)$ and $\operatorname{TFP}(\theta)$ can be illustrated by plots of $\operatorname{TFP}\left(\theta_{e}\right)-\operatorname{TFP}(\theta)$ (Fig. 9). Similar to the field of $G\left(\theta_{e}\right)-$ $G(\theta)$ (Fig. 5), high values of $\operatorname{TFP}(\theta)$ occur more frequently at higher latitudes, and high values of $\operatorname{TFP}\left(\theta_{e}\right)$ occur more frequently at low latitudes (Fig. 9). Also, high values of $\operatorname{TFP}\left(\theta_{e}\right)$ expand poleward in the summer hemispheres (Figs. 9a,c).

As further evidence of the importance of moisture in these quantities, Fig. 10 shows $\operatorname{TFP}(q)$. Immediately apparent is how regions of high $\operatorname{TFP}(q)$ are frequent at nearly all latitudes, especially when compared to the other quantities that have been presented so far. The high frequencies at low latitudes are because the mathematical expression for TFP in (2) incorporates higher derivatives, and moisture contains much more variability than temperature, especially in the more moist lower latitudes. The seasonal cycle of $\operatorname{TFP}(q)$ is very similar to that of $G(q)$ (cf. Figs. 10 and 6).

\section{c. Frontogenesis}

For Petterssen frontogenesis $F(\theta)$, its direct proportionality with $G(\theta)$ in (4) means that there is a lot of 


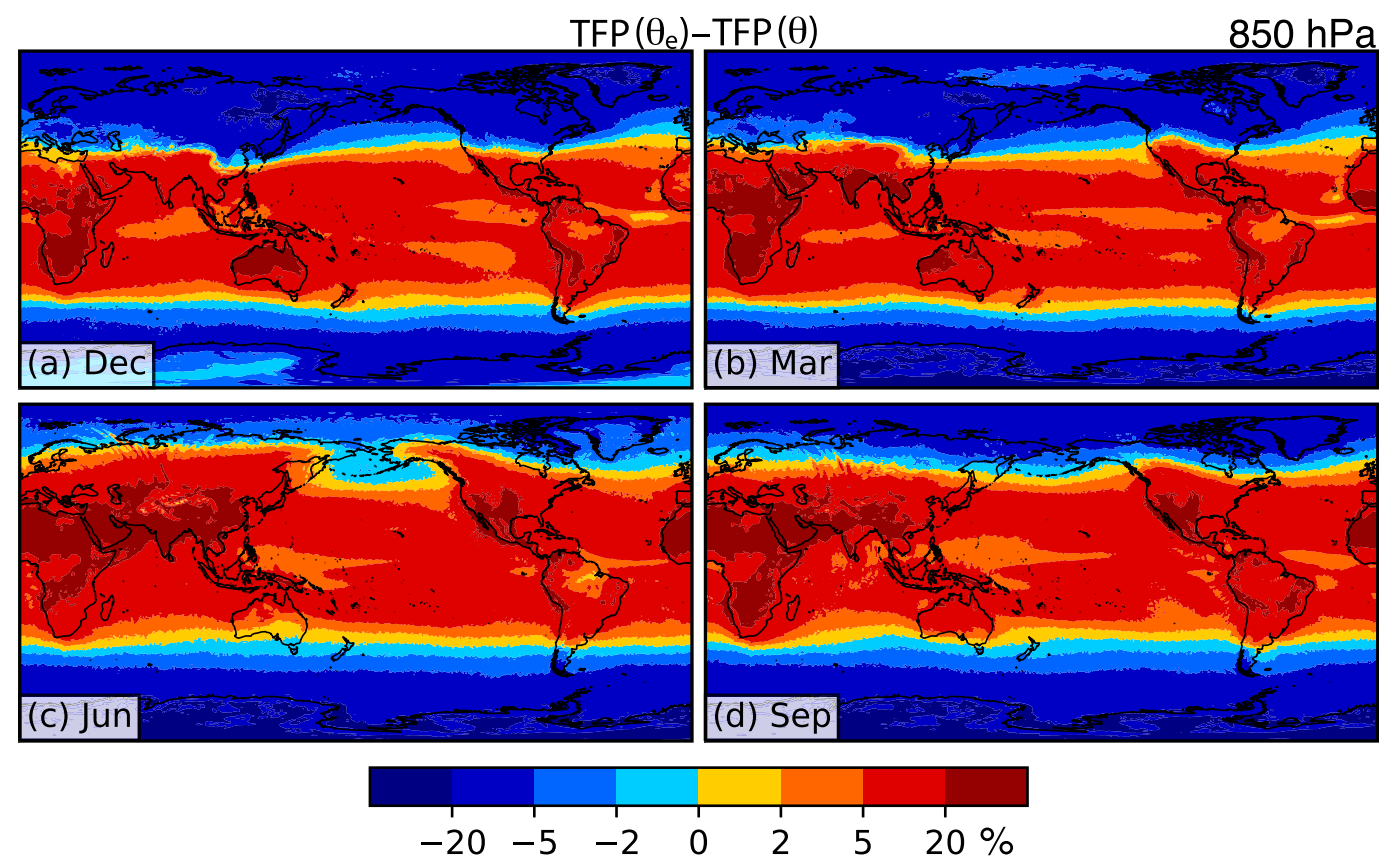

FIG. 9. Difference between the frequencies of $\operatorname{TFP}\left(\theta_{e}\right)$ in Fig. 7 and $\operatorname{TFP}(\theta)$ in Fig. 8 at $850 \mathrm{hPa}$ (\%; colored according to scale) for (a) December, (b) March, (c) June, and (d) September.

similarity between the two fields, particularly with the seasonal variations in position and intensity in the midlatitude storm tracks (cf. Figs. 3 and 11). However, the climatology of $F(\theta)$ does not show the maxima in the tropics associated with SST gradients that the climatologies of $G(\theta)$ or TFP $(\theta)$ possessed because these baroclinic zones were not associated with a frontogenetic wind field acting to increase the thermal gradient. As such, $F(\theta)$ appears to better discriminate real fronts from nonfrontal baroclinic zones (e.g., Fig. 2

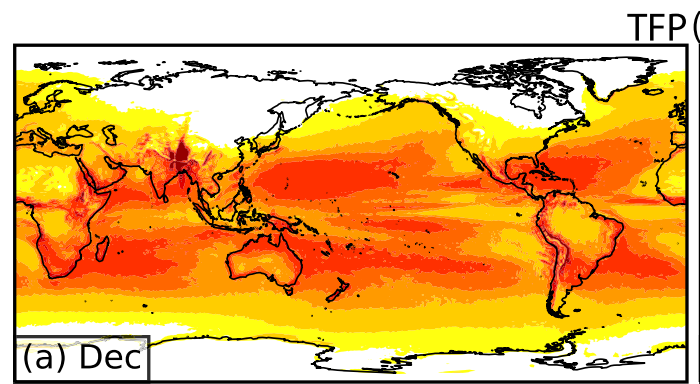

(q) $850 \mathrm{hPa}$
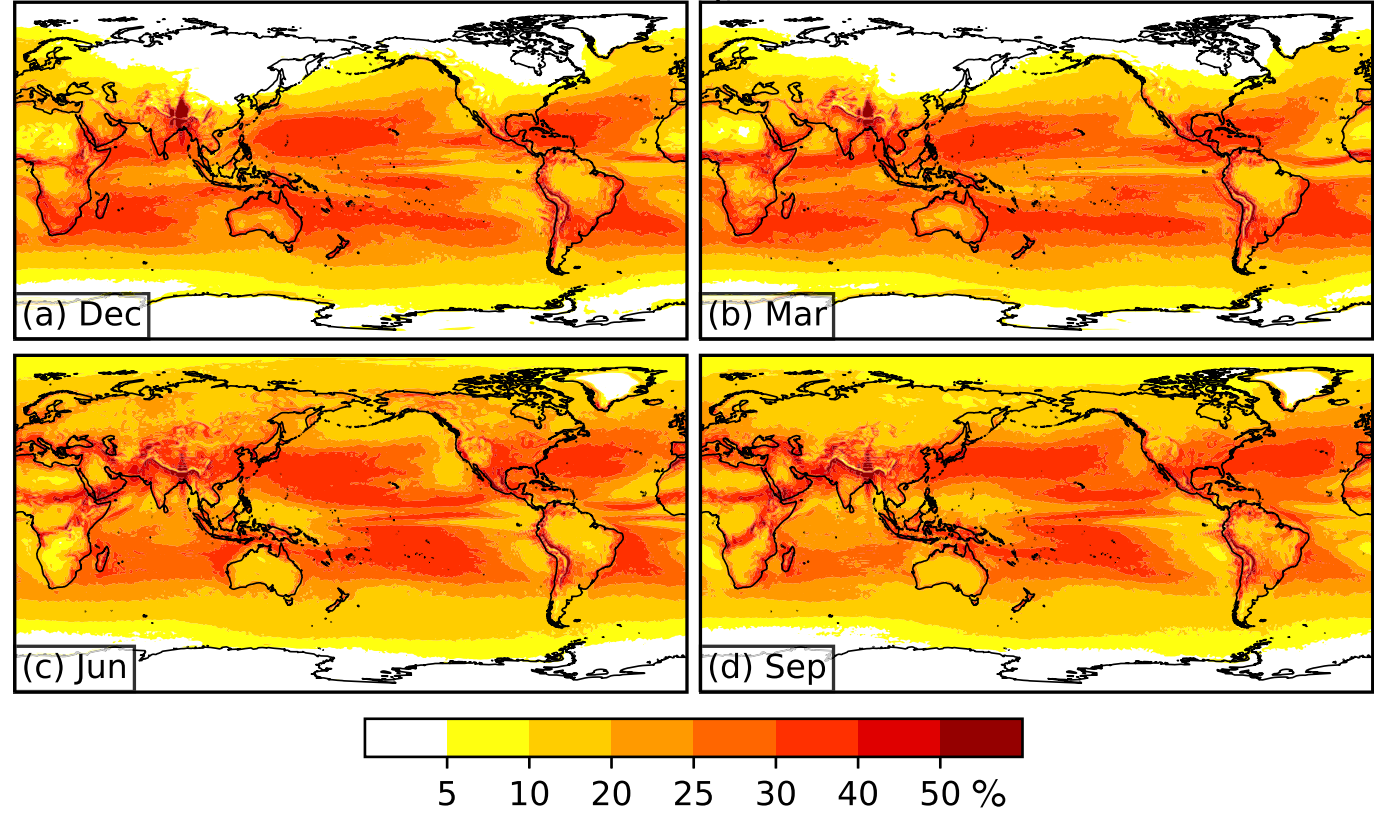

FIG. 10. Frequency of $850-\mathrm{hPa} \operatorname{TFP}(q)$ exceeding $0.5 \mathrm{~g} \mathrm{~kg}^{-1}(100 \mathrm{~km})^{-2}$ (\%, colored according to scale) for (a) December, (b) March, (c) June, and (d) September. 


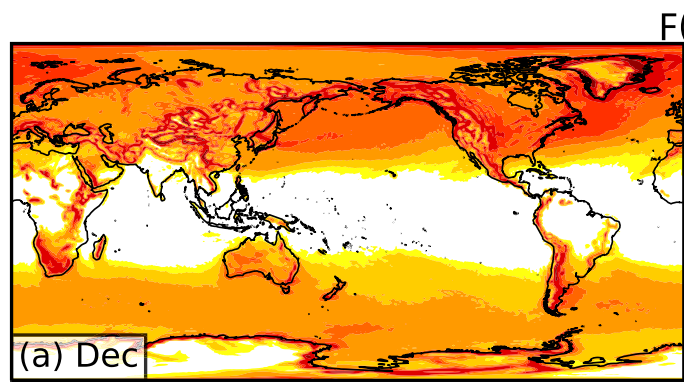

$\mathrm{F}(\theta)$ $850 \mathrm{hPa}$
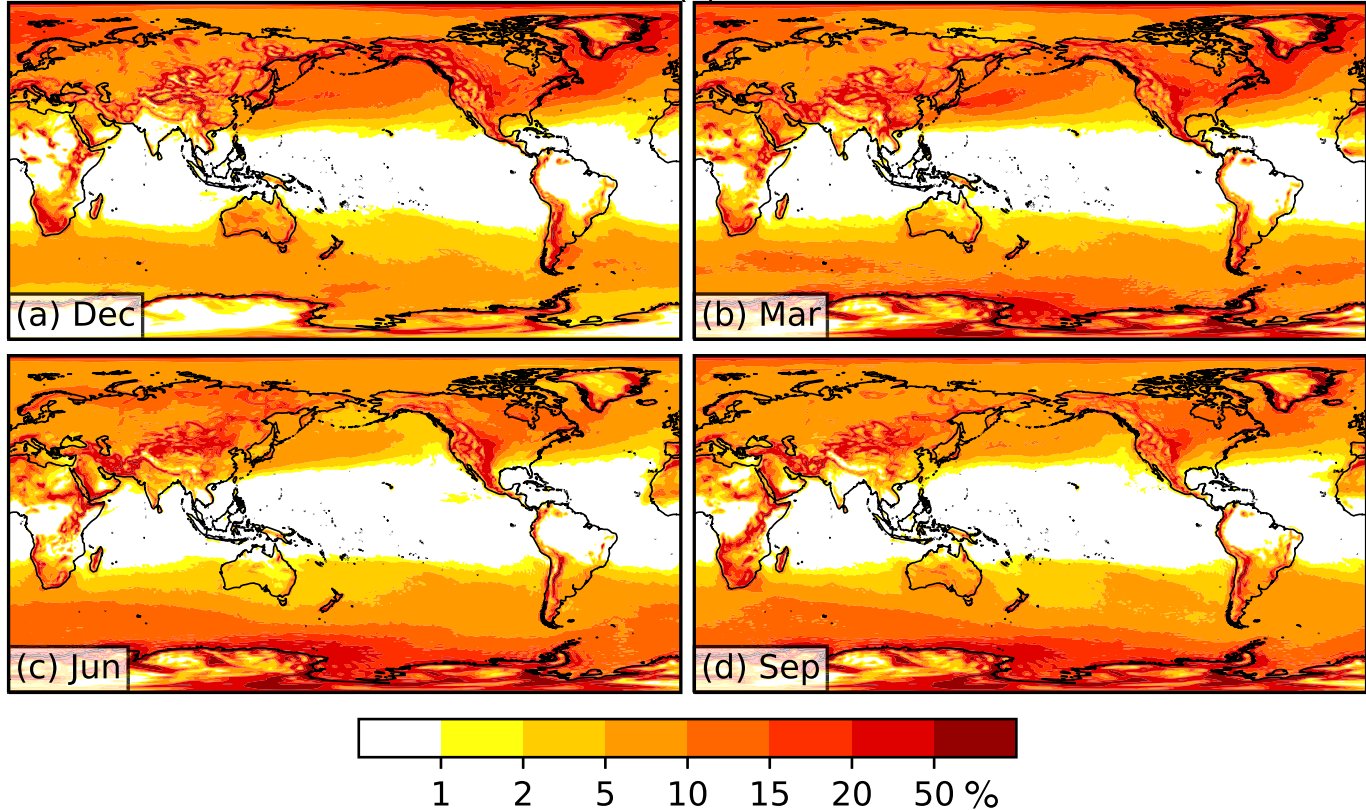

FIG. 11. Frequency of $850-\mathrm{hPa} F(\theta)$ exceeding $0.3 \mathrm{~K}(100 \mathrm{~km})^{-1} 3 \mathrm{~h}^{-1}$ (\%, colored according to scale) for (a) December, (b) March, (c) June, and (d) September.

in Sanders 1999) than either $G(\theta)$ or $\operatorname{TFP}(\theta)$. This is perhaps not surprising because Petterssen frontogenesis defines mathematically the physical process of strengthening a temperature gradient that produces fronts.
For comparison, climatologies of negative Petterssen frontogenesis (i.e., frontolysis) were also created (Fig. 12). The regions of frequent regions of frontolysis were similar to those for frontogenesis, although there were some minor quantitative differences (cf. Figs. 11 and 12).
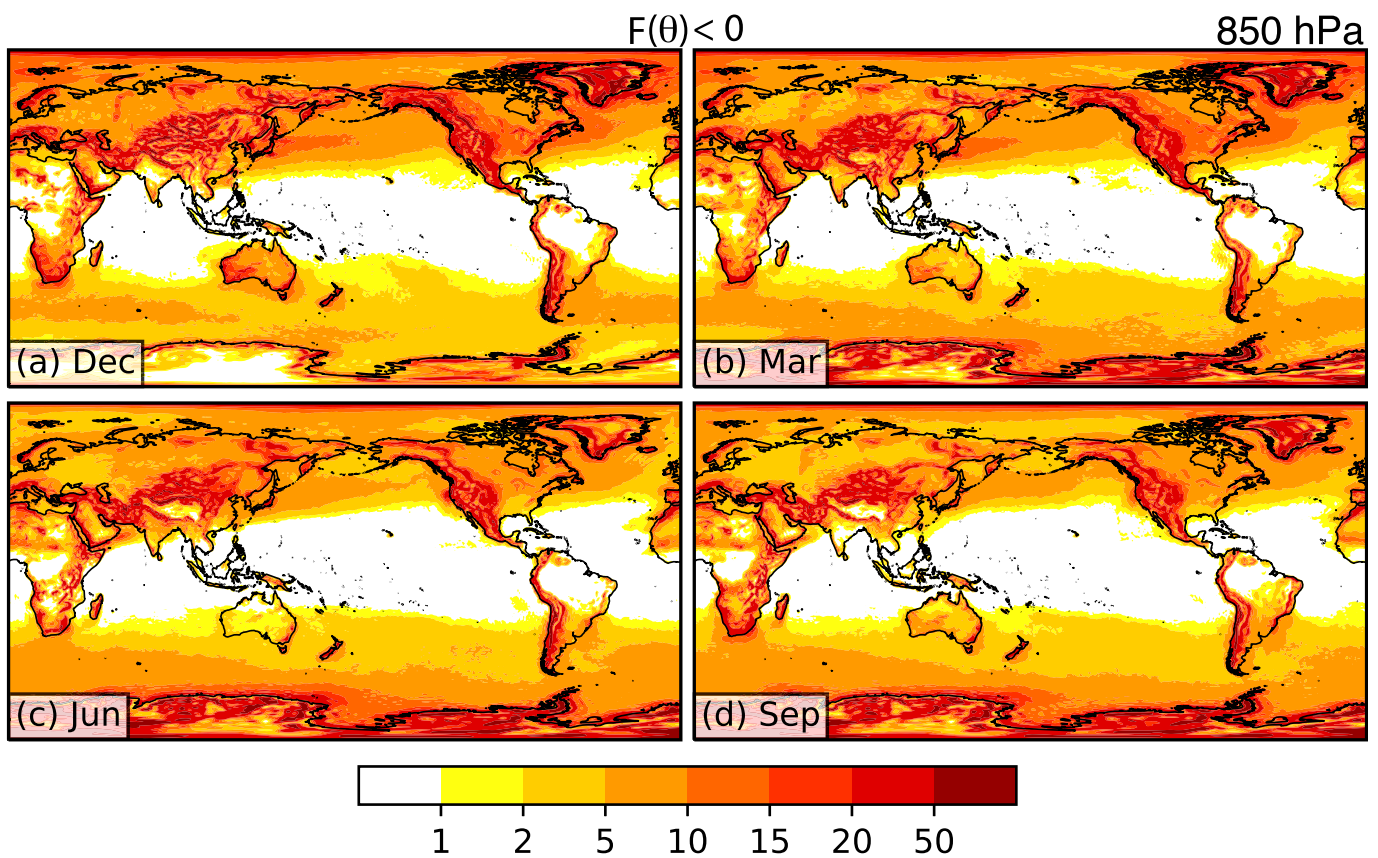

FIG. 12. Frequency of 850 -hPa Petterssen frontolysis $F(\theta)$ less than $-0.15 \mathrm{~K}(100 \mathrm{~km})^{-1}(3 \mathrm{~h})^{-1}(\%$, colored according to scale) for (a) December, (b) March, (c) June, and (d) September. 


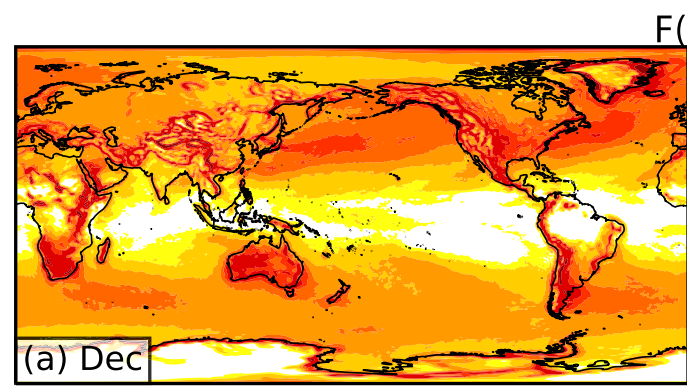

$\mathrm{F}\left(\theta_{\mathrm{e}}\right)$ $850 \mathrm{hPa}$
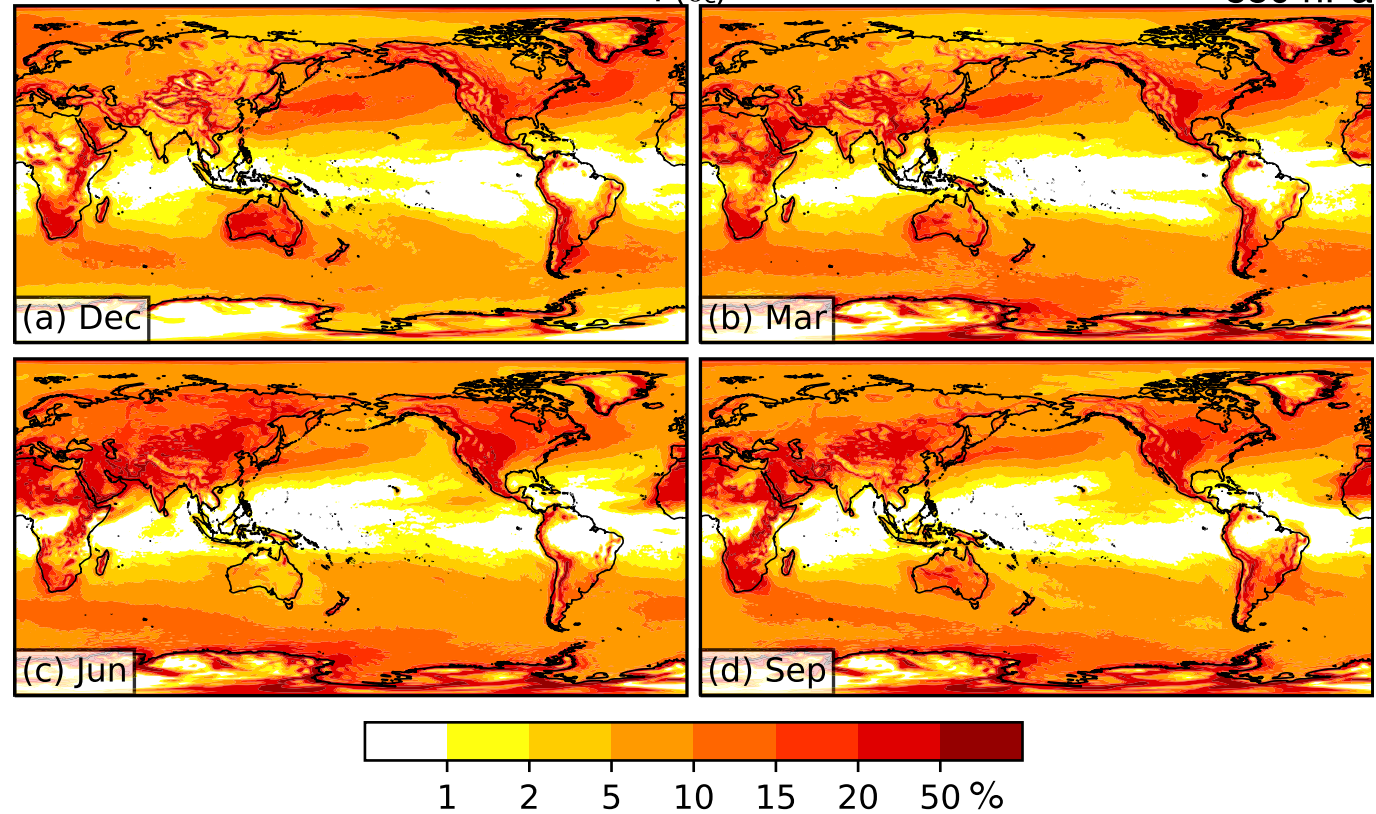

FIG. 13. Frequency of $850-\mathrm{hPa} F\left(\theta_{e}\right)$ exceeding $0.5 \mathrm{~K}(100 \mathrm{~km})^{-1} 3 \mathrm{~h}^{-1}$ (\%, colored according to scale) for (a) December, (b) March, (c) June, and (d) September.

When $\theta_{e}$ is used in the frontogenesis function, the similarity between $G\left(\theta_{e}\right)$ and $F\left(\theta_{e}\right)$ is also apparent (cf. Figs. 4 and 13). Frequencies of $F\left(\theta_{e}\right)$ at higher latitudes are more similar to $F(\theta)$ than to $G\left(\theta_{e}\right)$, whereas features at low latitudes (such as those in the eastern ocean basins) are more similar to those in $G\left(\theta_{e}\right)$ than $F(\theta)$ (cf. Figs. 13, 4, and 11). These similarities suggest that in the midlatitudes where extratropical cyclones actively create fronts, $F$ is a useful function for identifying fronts regardless of the thermodynamic quantity, whereas at

$F(q)$
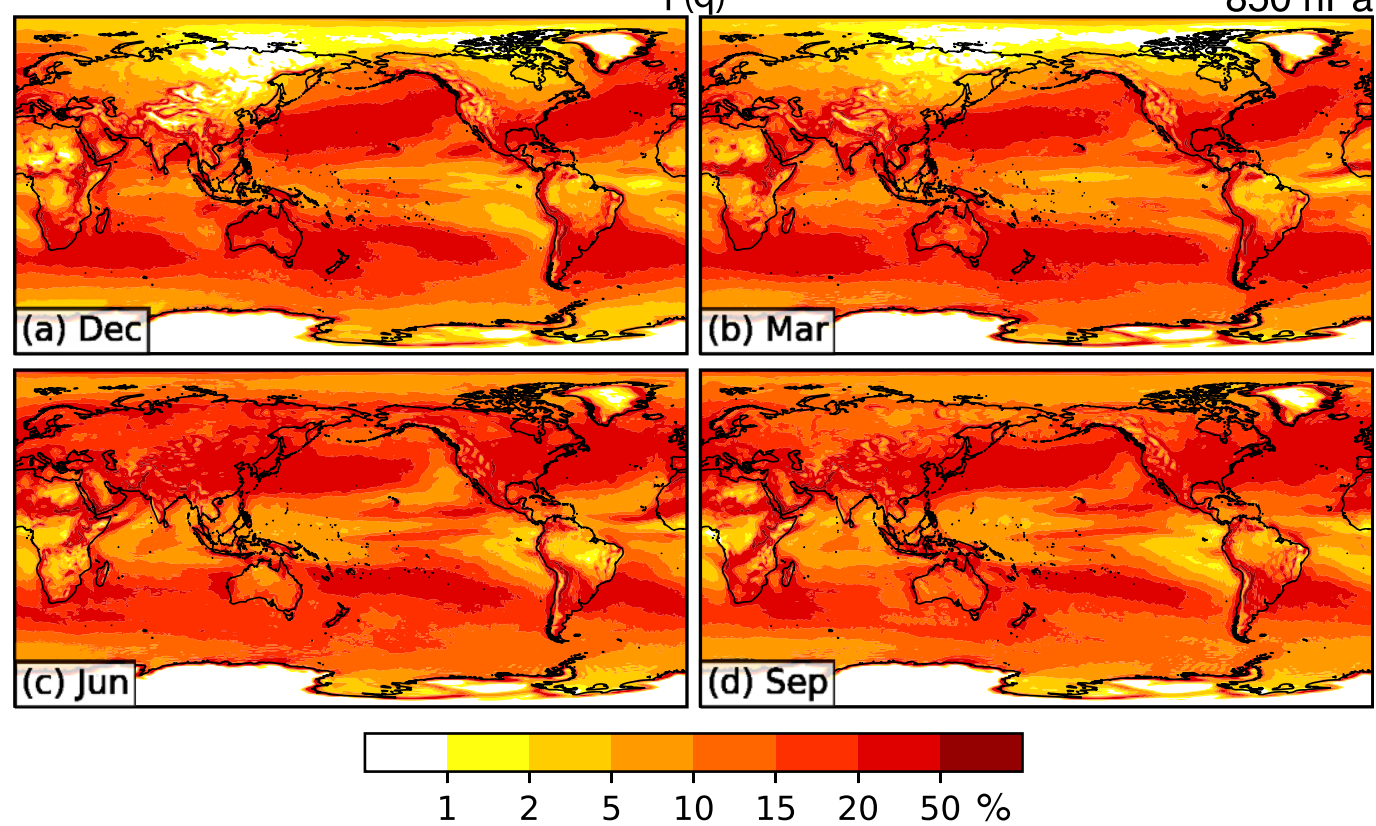

FIG. 14. Frequency of $850-\mathrm{hPa} F(q)$ exceeding $0.1 \mathrm{~g} \mathrm{~kg}^{-1}(100 \mathrm{~km})^{-1} 3 \mathrm{~h}^{-1}$ (\%, colored according to scale) for (a) December, (b) March, (c) June, and (d) September. 


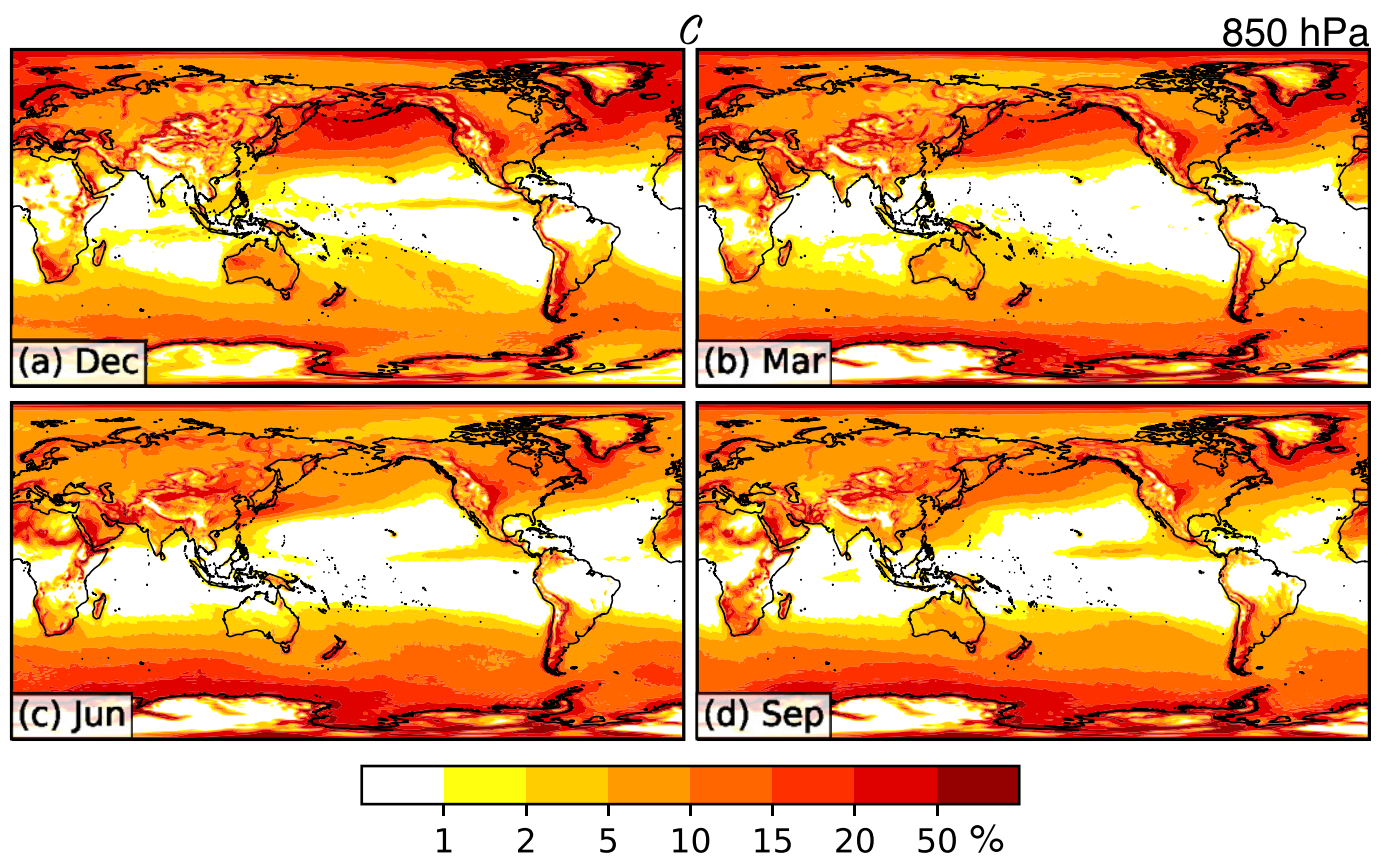

FIG. 15. Frequency of $850-\mathrm{hPa}$ asymptotic contraction rate $\mathcal{C}$ exceeding $0.3 \mathrm{~s}^{-1}$ (\%, colored according to scale) for (a) December, (b) March, (c) June, and (d) September.

low latitudes, frontogenesis of gradients of moisture gradients becomes more common.

The spatial maps of $F\left(\theta_{e}\right)-F(\theta)$ turn out to be quite similar to those of $G\left(\theta_{e}\right)-G(\theta)$ (Fig. 5) so are not shown here. However, we show the climatology of $F(q)$ to illustrate the kinematic effects that the $850-\mathrm{hPa}$ wind field has on increasing gradients in the moisture field by bringing lines of constant mixing ratio together (Fig. 14). For example, $F(q)$ has been used to demonstrate the intensification of a southern Great Plains dryline (Buban et al. 2007) and of a northern Australia dryline (Arnup and Reeder 2007). For the global climatology, much of the globe is covered by regions of frequent $F(q)$ (Fig. 14). The principal maxima along the storm tracks in each hemisphere (Fig. 14) are much broader and at lower latitudes with higher frequencies $(>20 \%)$ than for any other similar climatology in the present study. Values exceed $50 \%$ in the lee of the Rockies in June and September and along the southern slopes of the Himalaya throughout the year. There are also local maxima of high frequency along the South Pacific and South Atlantic convergence zones, as well as near the equator, in part associated with the convergence of the trade winds along the ITCZ.

\section{d. Asymptotic contraction rate}

Although the asymptotic contraction rate $\mathcal{C}$ does not include any thermodynamic variable and is a function of wind only, its climatology (Fig. 15) bears some similarities to thermal-based climatologies such as $G(\theta)$ and $F(\theta)$ (cf. Figs. 3, 11, 15). Regions associated with the storm tracks in both hemispheres are present, similar to $G(\theta)$ and $F(\theta)$, but with some differences. Specifically, the region associated with the storm track in the Southern Hemisphere is similar to that of $F(\theta)$, but closer to Antarctica than in $G(\theta)$. The maxima in the $\mathcal{C}$ climatology associated with the Northern Hemisphere storm tracks are farther poleward in September through March, but more equatorward in June than for either $G(\theta)$ or $F(\theta)$, consistent with the mei-yu front along the East Asian coast becoming active at this time (Fig. 15).

In the tropics, a narrow maximum occurs across the Pacific Ocean (June-December; Figs. 15c,d,a) and the Indian Ocean (September-December; Figs. 15d,a), broadly consistent with the location of the ITCZ in the reanalyses (Žagar et al. 2011). Maxima over northern Africa in June and September (Figs. 15c,d) are consistent with a region of $925-\mathrm{hPa}$ wind convergence in Fig. 9 of Nicholson (2018), but other maxima during other seasons are not replicated in our Figs. 15a and 15b.

\section{Climatologies at the surface}

All climatologies in this present article so far were presented at $850 \mathrm{hPa}$. No other published frontal climatological studies using gridded datasets have compared results calculated from thermodynamic variables 


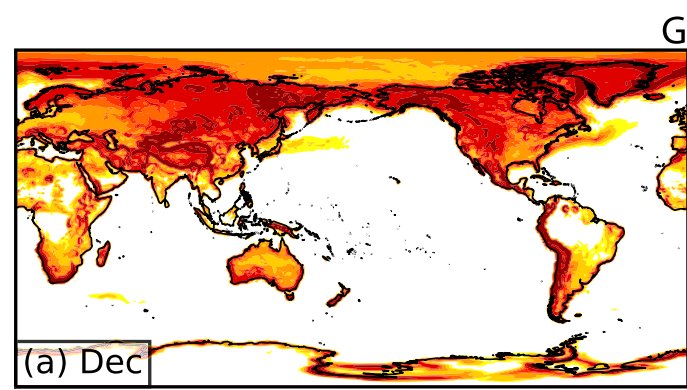

$\mathrm{G}(\theta)$
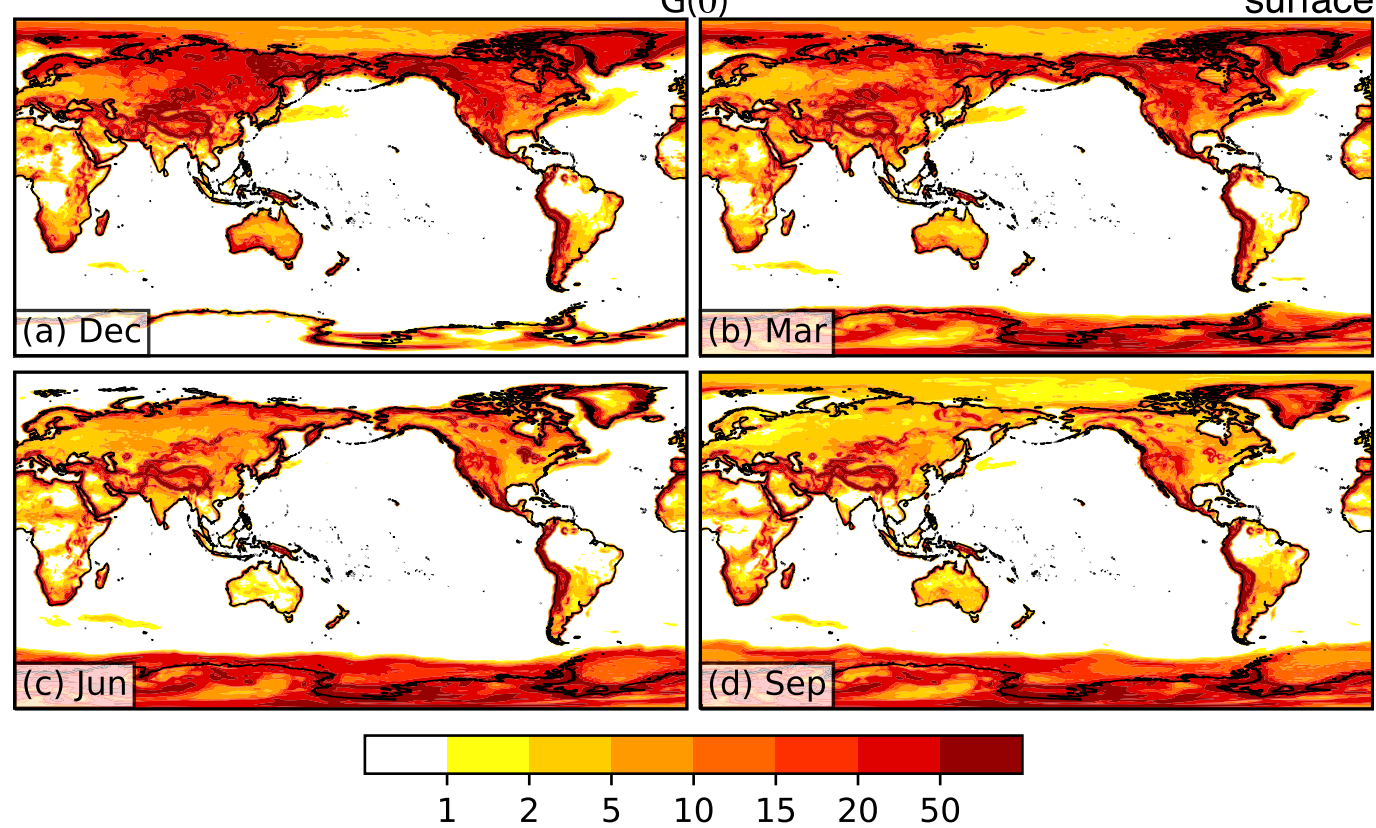

FIG. 16. Frequency of $G(\theta)$ at the surface exceeding $3.3 \mathrm{~K}(100 \mathrm{~km})^{-1}$ (\%, colored according to scale) for (a) December,

(b) March, (c) June, and (d) September.

between $850 \mathrm{hPa}$ and the surface. [Recall that Simmonds et al. (2012) calculated their climatology at both $850 \mathrm{hPa}$ and the surface using a wind-based diagnostic.] We compare climatologies of thermodynamic variables at $850 \mathrm{hPa}$ (section 4) with those at the surface in this section.

Figure 16 shows surface $G(\theta)$ at a threshold of $3.3 \mathrm{~K}$ $(100 \mathrm{~km})^{-1}$, which is less than the values used by Sanders (1999) and Sanders and Hoffman (2002), who adopted $4 \mathrm{~K}(100 \mathrm{~km})^{-1}$ for a moderate baroclinic zone and $8 \mathrm{~K}(100 \mathrm{~km})^{-1}$ for a strong baroclinic zone. Although Sanders's definitions produce abundant fronts over North America, these thresholds produce few fronts over the oceans, over Europe, and in the Southern Hemisphere (not shown), so the Sanders threshold is too high for producing a global climatology. Thus, our lower threshold of $3.3 \mathrm{~K}(100 \mathrm{~km})^{-1}$ is consistent with the view that about $10 \%$ of the global map being covered with fronts appears to be about the right amount (section 2d).

The climatology of surface $G(\theta)$ is surprisingly different from that at $850 \mathrm{hPa}$ (cf. Figs. 3 and 16). Even with the lower threshold, frequent gradients at the surface exceeding the threshold (more than $20 \%$ of the time) are confined almost entirely to the land, over the Gulf Stream and Kuroshio, and over polar sea ice during the cool season (Fig. 16). In contrast, the regions of high frequency associated with the storm tracks over the ocean are absent, occurring less than $1 \%$ of the time, except for along the Gulf Stream, Kuroshio, and Southern Ocean southeast of Africa (Fig. 16). This result confirms the necessity for looking above the surface if identifying strong gradients in temperature over the oceans is required.

The climatology of surface $G\left(\theta_{e}\right)$ in Fig. 17 has a similar behavior. The frequency of exceeding the threshold for surface $G\left(\theta_{e}\right)$ is less common over the oceans than over the land than for $G\left(\theta_{e}\right)$ at $850 \mathrm{hPa}$, and these locations are at much lower latitudes throughout the year with frequencies exceeding $2 \%$ in the stormtrack regions (except along the Antarctic coastline in June and September). The frequencies over land also tend to be higher during the summer than the winter. For example, $G\left(\theta_{e}\right)$ exceeds the threshold over $20 \%$ of the time over Asia and North America in June, and $G\left(\theta_{e}\right)$ exceeds the threshold over $50 \%$ of the time over Australia in December (cf. Figs. 17a,c). The maxima along the upwelling zones in the eastern ocean basins that were present at $850 \mathrm{hPa}$ are not present at the surface (cf. Figs. 4 and 17), perhaps because they are not strong enough to exceed the threshold frequently enough.

Similar behavior occurs with the climatology of surface $\operatorname{TFP}(\theta)$ in Fig. 18. In contrast to the climatology of surface $G(\theta)$ in Fig. 16, the climatology of surface $\operatorname{TFP}(\theta)$ shows more structure over the ocean with frequencies exceeding $2 \%$ in the storm-track regions. The field, however, is noisy over both the land and the ocean (Fig. 18), due in part to the higher number of derivatives 


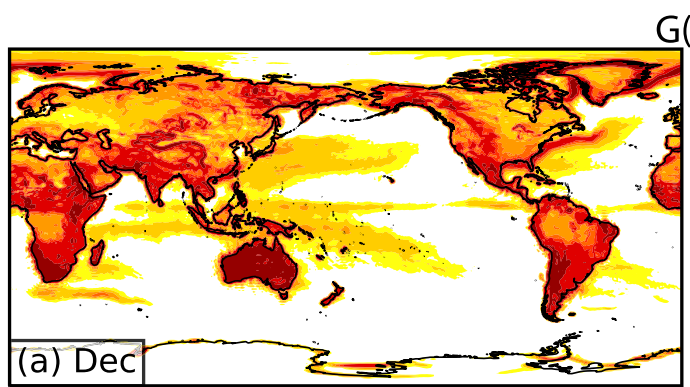

$\mathrm{G}\left(\theta_{\mathrm{e}}\right)$ surface
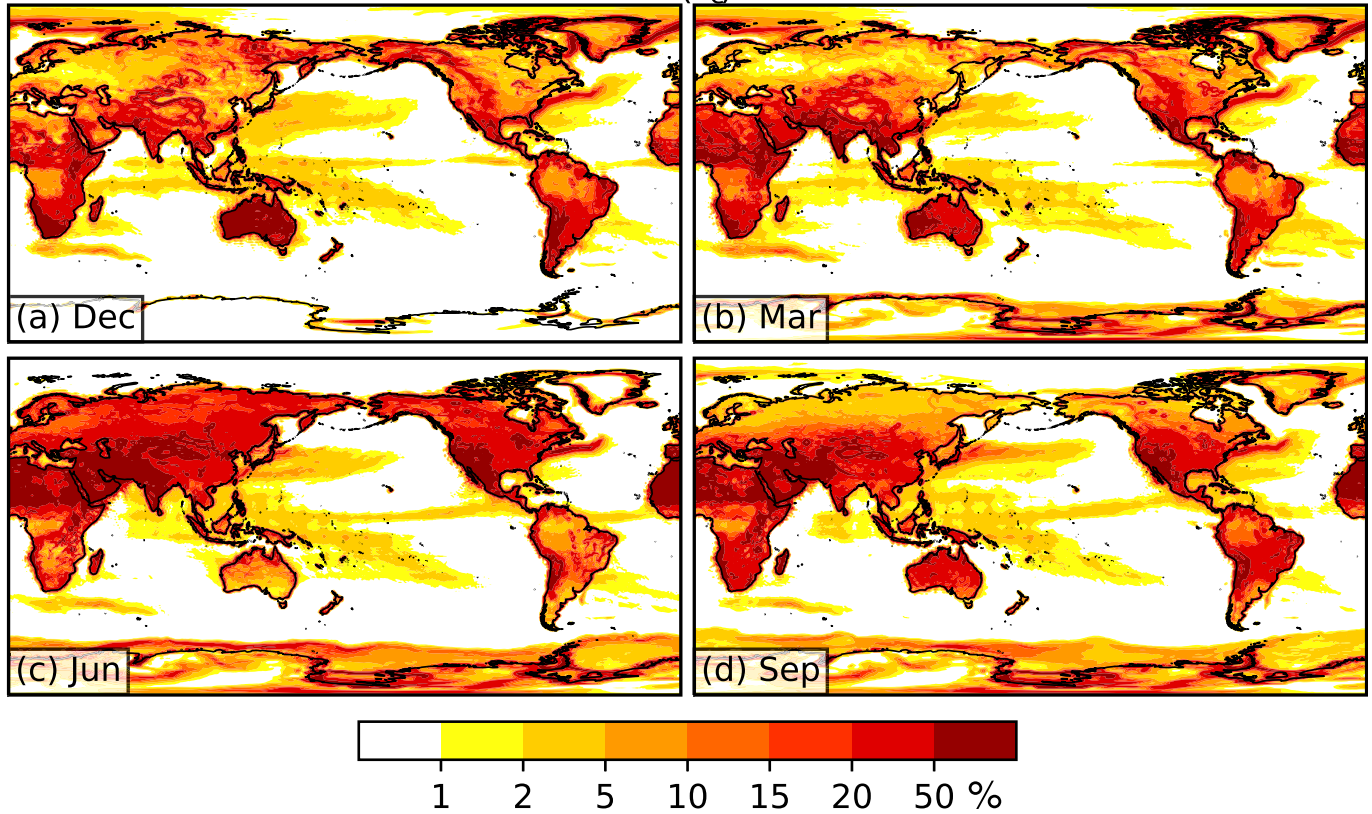

FIG. 17. Frequency of $G\left(\theta_{e}\right)$ at the surface exceeding $6.2 \mathrm{~K}(100 \mathrm{~km})^{-1}$ (\%, colored according to scale) for (a) December, (b) March, (c) June, and (d) September.

in calculating TFP. The patterns in the field lack the smoothness of $\operatorname{TFP}(\theta)$ at $850 \mathrm{hPa}$ (Fig. 7), again suggesting that the fronts are weakened over the ocean relative to the land and that $850 \mathrm{hPa}$ provides a very different perspective on the frequency of fronts than the surface. Local maxima of baroclinic zones appear around the Great Lakes in all seasons, as has been noted previously (e.g., Hoffman 2008).

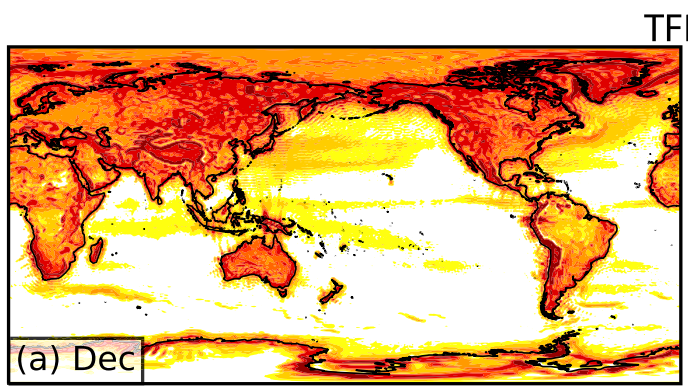

$\operatorname{TFP}(\theta)$
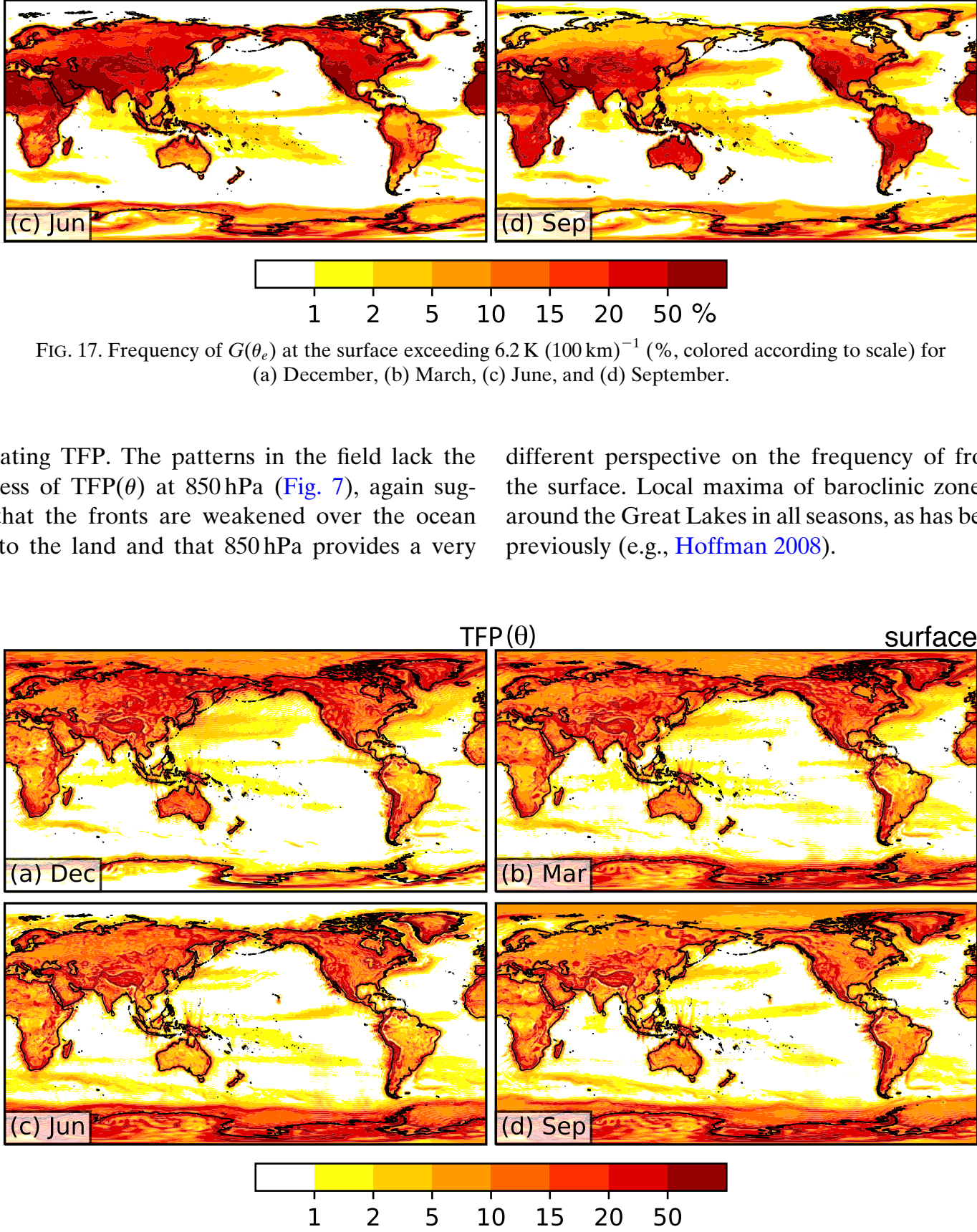

FIG. 18. Frequency of $\operatorname{TFP}(\theta)$ at the surface exceeding $1.35 \mathrm{~K}(100 \mathrm{~km})^{-2}$ (\%, colored according to scale) for (a) December, (b) March, (c) June, and (d) September. 


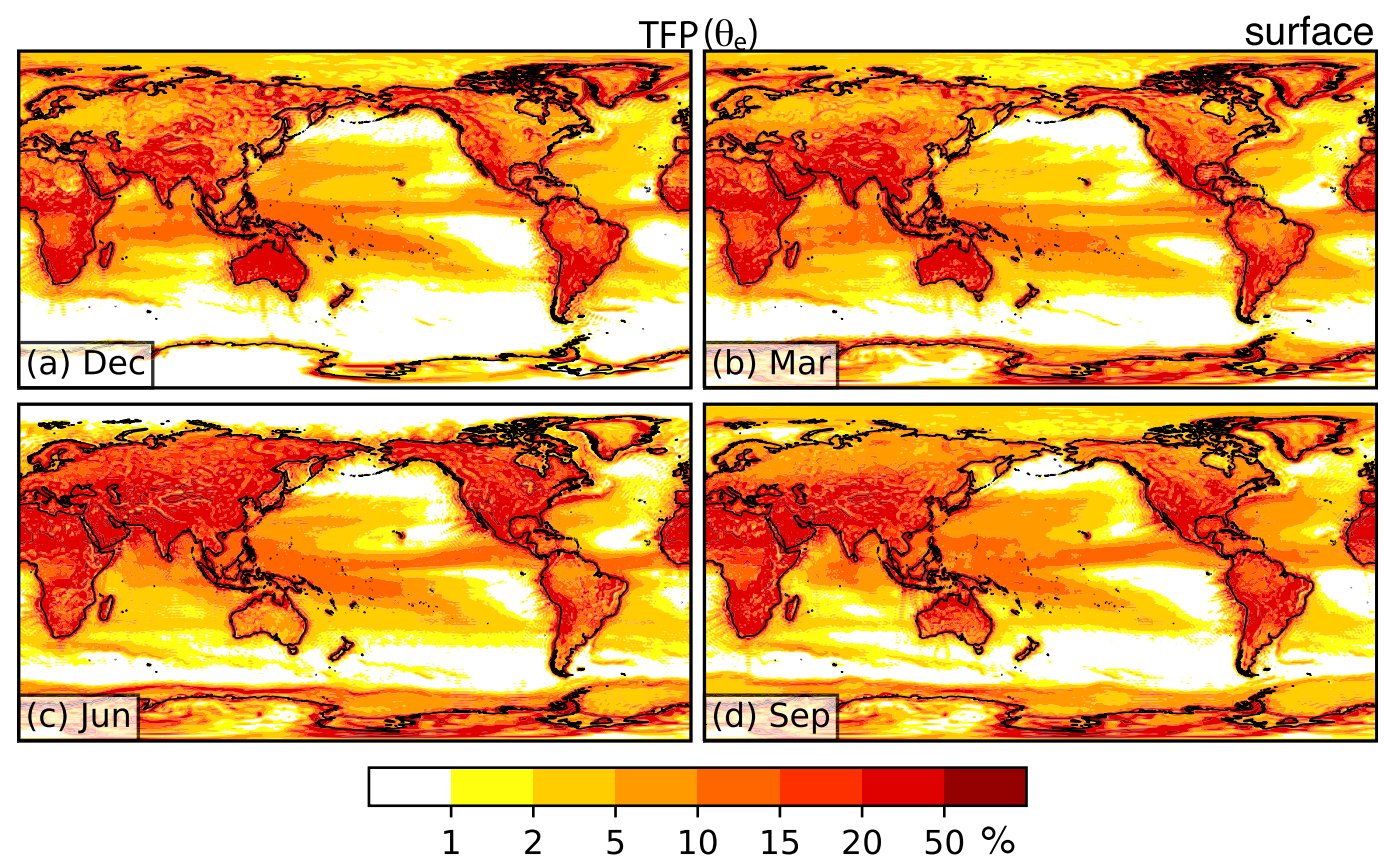

FIG. 19. Frequency of $\operatorname{TFP}\left(\theta_{e}\right)$ at the surface exceeding $2.8 \mathrm{~K}(100 \mathrm{~km})^{-2}(\%$, colored according to scale) for (a) December, (b) March, (c) June, and (d) September.

Features exceeding the threshold of surface $\operatorname{TFP}\left(\theta_{e}\right)$ are further emphasized at low levels in Fig. 19, which again indicates how climatologies derived from $\theta_{e}$ and TFP produce low-latitude structure that would be inconsistent with the expectations of fronts being common in the midlatitudes. Thus, given these large differences from expectations, extrapolating frontal climatologies from $850 \mathrm{hPa}$ to the surface for either $G$ or TFP is generally ill advised.

In contrast, the climatology of surface $F(\theta)$ is much smoother than that of surface $\operatorname{TFP}(\theta)$ and looks similar to that at $850 \mathrm{hPa}$ (cf. Figs. 18, 20, and 11). Whereas values of 850 -hPa $F(\theta)$ across the North Pacific and North Atlantic Ocean basins exceed the threshold 5\%$10 \%$ of the time, these values occur only $1 \%-2 \%$ of the time over the eastern ocean basins, suggesting the toll that air-sea interaction takes on the near-surface temperature gradients as fronts traverse the ocean in the storm tracks. Plots of frontolysis at the surface are similar to those of frontogenesis at the surface, except for reduced frequencies (cf. Figs. 20 and 21), similar to that at $850 \mathrm{hPa}$ (cf. Figs. 11 and 12). Local maxima in $F(\theta)$ frontogenesis and frontolysis around the Great Lakes are prominent, indicating the frontogenetic and frontolytic effects of the lakes on fronts.

The maxima of $F\left(\theta_{e}\right)$ at the surface are better defined than the same features for $F\left(\theta_{e}\right)$ at $850 \mathrm{hPa}$ (cf. Figs. 22 and 13). The maxima of $F\left(\theta_{e}\right)$ at the surface are also broadly similar to those of $F(\theta)$ at the surface, although slightly shifted equatorward and more frequent (cf. Figs. 22 and 20), consistent with previous climatologies that use $\theta_{e}$, compared to $\theta$.

Finally, we present the climatology for the asymptotic contraction rate $\mathcal{C}$ at the surface (Fig. 23). Unlike the climatologies of $G(\theta)$ at $850 \mathrm{hPa}$ and the surface (cf. Figs. 3 and 16), values exceeding the threshold of $\mathcal{C}$ at $850 \mathrm{hPa}$ are more frequent over the land and less frequent over the ocean than those for $\mathcal{C}$ at the surface (cf. Figs. 15 and 23). The climatology of $\mathcal{C}$ at the surface reveals small-scale features of high frequency around the Great Lakes throughout the year (e.g., Keen and Lyons 1978; Laird et al. 2001); over the Gulfs of Tehuantepec, Papagayo, and Panama in December and March due to winds through gaps in the mountains (e.g., Hurd 1929; Parmenter 1970; Trasviña Castro et al. 1995; Schultz et al. 1997, 1998; Steenburgh et al. 1998); and along the ITCZ in June through December (Fig. 23). As such, the asymptotic contraction rate demonstrates its strength in identifying airstream boundaries not only at $850 \mathrm{hPa}$, but also at the surface. At the surface, however, many of the maxima of frequent $\mathcal{C}$ would not be considered fronts or front-like.

\section{Defining fronts, airmass boundaries, and airstream boundaries}

Establishing the properties that define a front has been controversial through time (e.g., Gold 1935; 


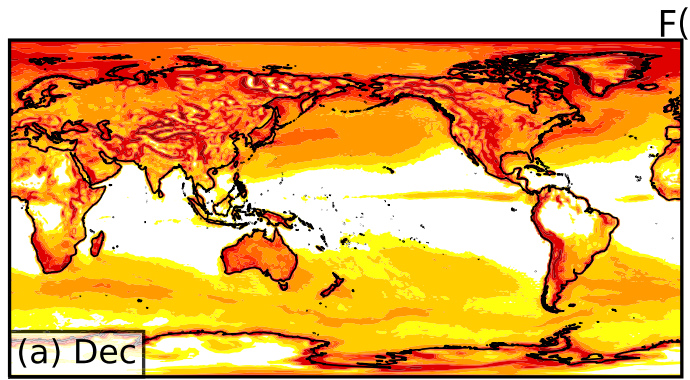

$\mathrm{F}(\theta)$ surface
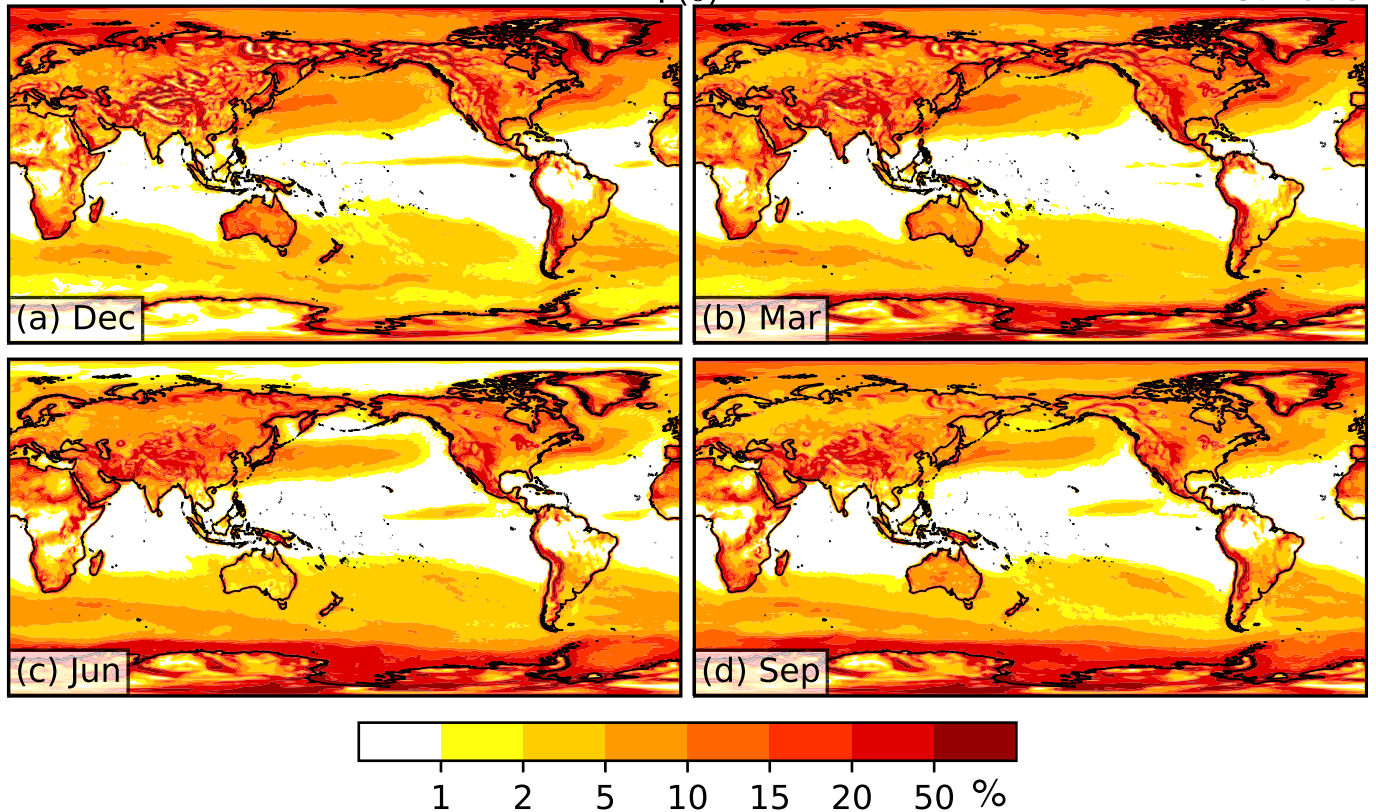

FIG. 20. Frequency of Petterssen frontogenesis $F(\theta)$ at the surface exceeding $0.275 \mathrm{~K}(100 \mathrm{~km})^{-1}(3 \mathrm{~h})^{-1}(\%$, colored according to scale) for (a) December, (b) March, (c) June, and (d) September.

Douglas 1952; Sanders and Doswell 1995; Schemm et al. 2018; Thomas and Schultz 2019). In this study, we explored the results of applying various putative, and potential, definitions for fronts in constructing global climatologies. So far, we have used the term front rather loosely in this article. In this section, we wish to delve more critically into the definition of a front, as well as definitions of airmass boundary and airstream boundary,
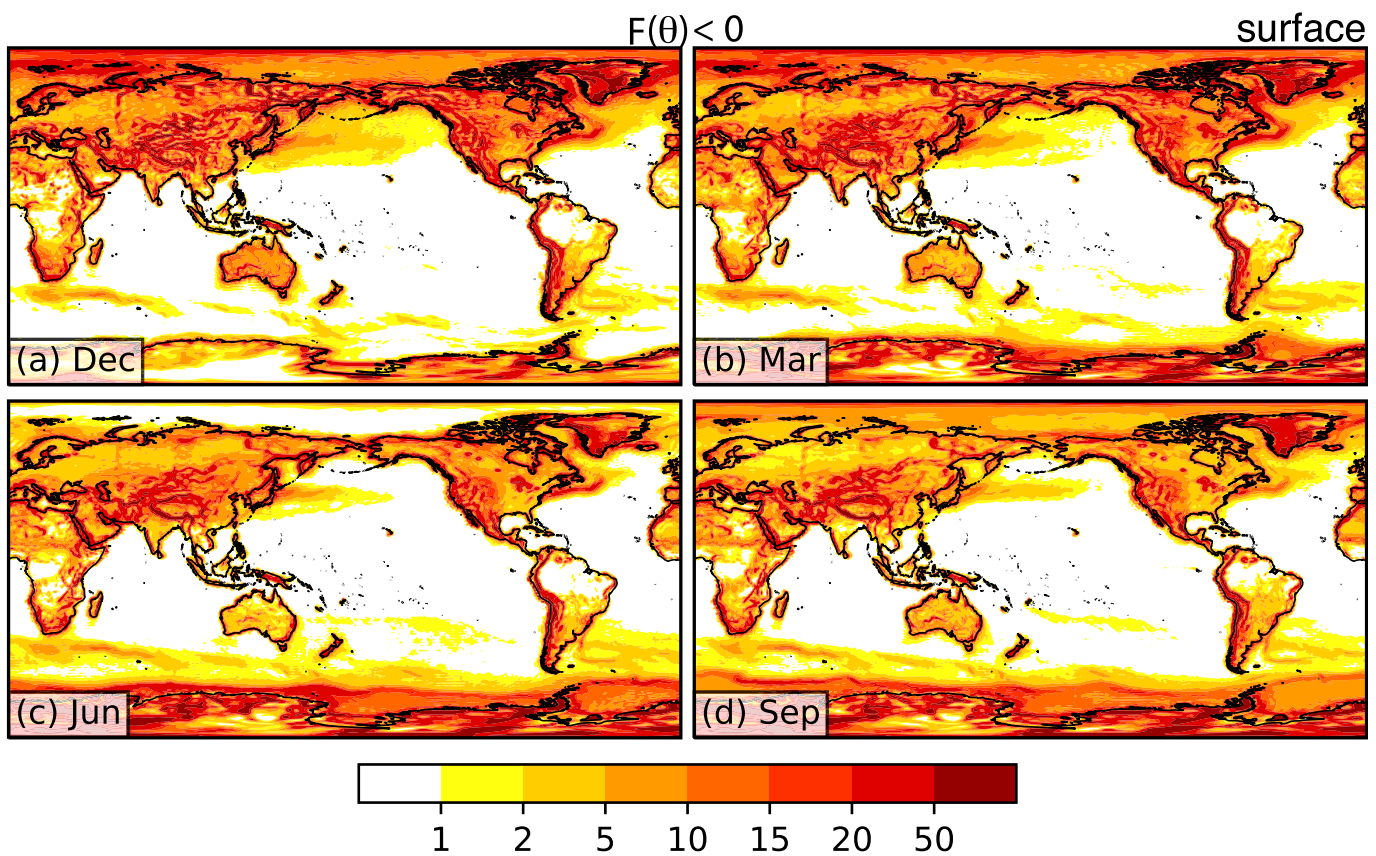

FIG. 21. Frequency of Petterssen frontolysis $F(\theta)$ at the surface less than $-0.18 \mathrm{~K}(100 \mathrm{~km})^{-1}(3 \mathrm{~h})^{-1}(\%$, colored according to scale) for (a) December, (b) March, (c) June, and (d) September. 


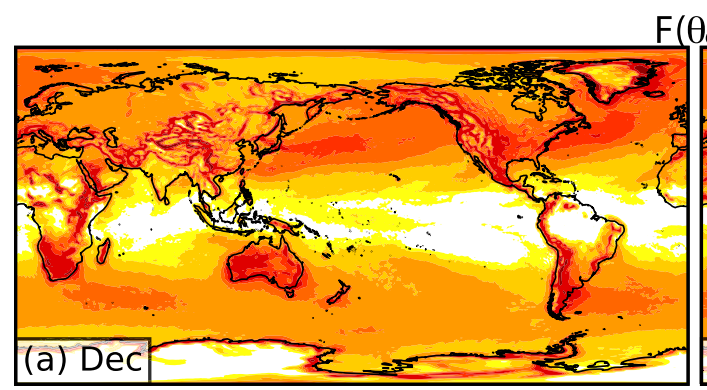

$\mathrm{F}\left(\theta_{\mathrm{e}}\right)$ surface
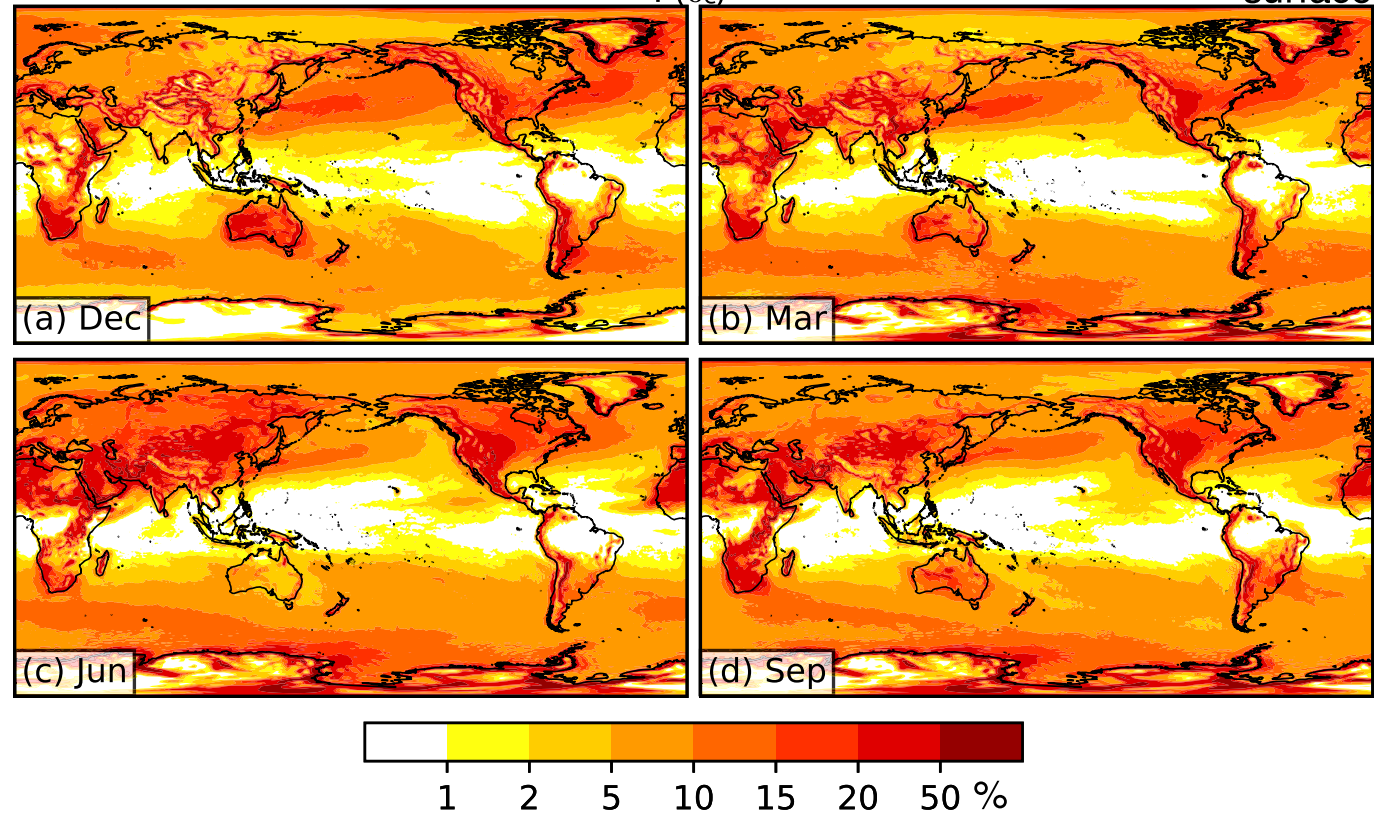

FIG. 22. Frequency of $F\left(\theta_{e}\right)$ at the surface exceeding $0.055 \mathrm{~K}(100 \mathrm{~km})^{-1}(3 \mathrm{~h})^{-1}$ (\%, colored according to scale) for (a) December, (b) March, (c) June, and (d) September.

and how these definitions are applied to global climatologies. Specifically, we recall the five choices used to define a front in section 1 . Given the results from the present article, we revisit the implications of three of these choices in this section.

\section{a. Quantities to define a front versus an airmass boundary}

The first choice was the quantity. Various analysts have recommended a number of different quantities that could be used to identify a front (section $2 a$ ). The debate on how to define a front rages on in part because analysts cannot agree on the quantities that define a front versus those that are merely associated with a front. Sanders and Doswell (1995) argued that true fronts should be regarded as density discontinuities. Because the density contrast is most easily measured by the temperature (strictly speaking, the virtual temperature), fronts should be defined based on temperature or potential temperature. Note that this dynamically based definition does not conflict with the need for operational or research-based surface analysis that has a different purpose and may analyze nonfrontal features such as drylines, troughs, convergence boundaries, or mesoscale boundaries (e.g., Young and Fritsch 1989) that may be associated with sensible weather and may be worth identifying on a surface chart.

The choice of potential temperature for fronts, however, does not mean equivalent potential temperature is not useful. Because of the strong effect of moisture on the equivalent potential temperature, $\theta_{e}$ can be useful for identifying airmass boundaries-boundaries between horizontally widespread regions of air relatively homogeneous in temperature and moisture content. Defining airmass boundaries in terms of equivalent potential temperature may be useful, particularly in the tropics and subtropics where temperature gradients are weaker. Indeed, the climatologies using $\theta_{e}$ (Figs. 4, 8, and 13) show some utility in this regard, highlighting airmass boundaries that would not normally be considered fronts.

\section{b. Functions to define a front versus an airstream boundary}

With the diagnostic quantity identified, attention turns to the second choice: a mathematical function to define a front. Gradient and thermal front parameter have been shown to be effective functions, both in practical analysis and in climatologies. The function $G(\theta)$ works well for identifying fronts, and $G\left(\theta_{e}\right)$ works well for identifying airmass boundaries. TFP has the disadvantage that fields with larger variability will be more sensitive to the higher number of derivatives. Thus, expressions containing humidity (e.g., mixing ratio, $\theta_{e}$ ) may be more noisy with airmass boundaries being identified at low latitudes, compared to temperature-based expressions, unless filtered in some way. 


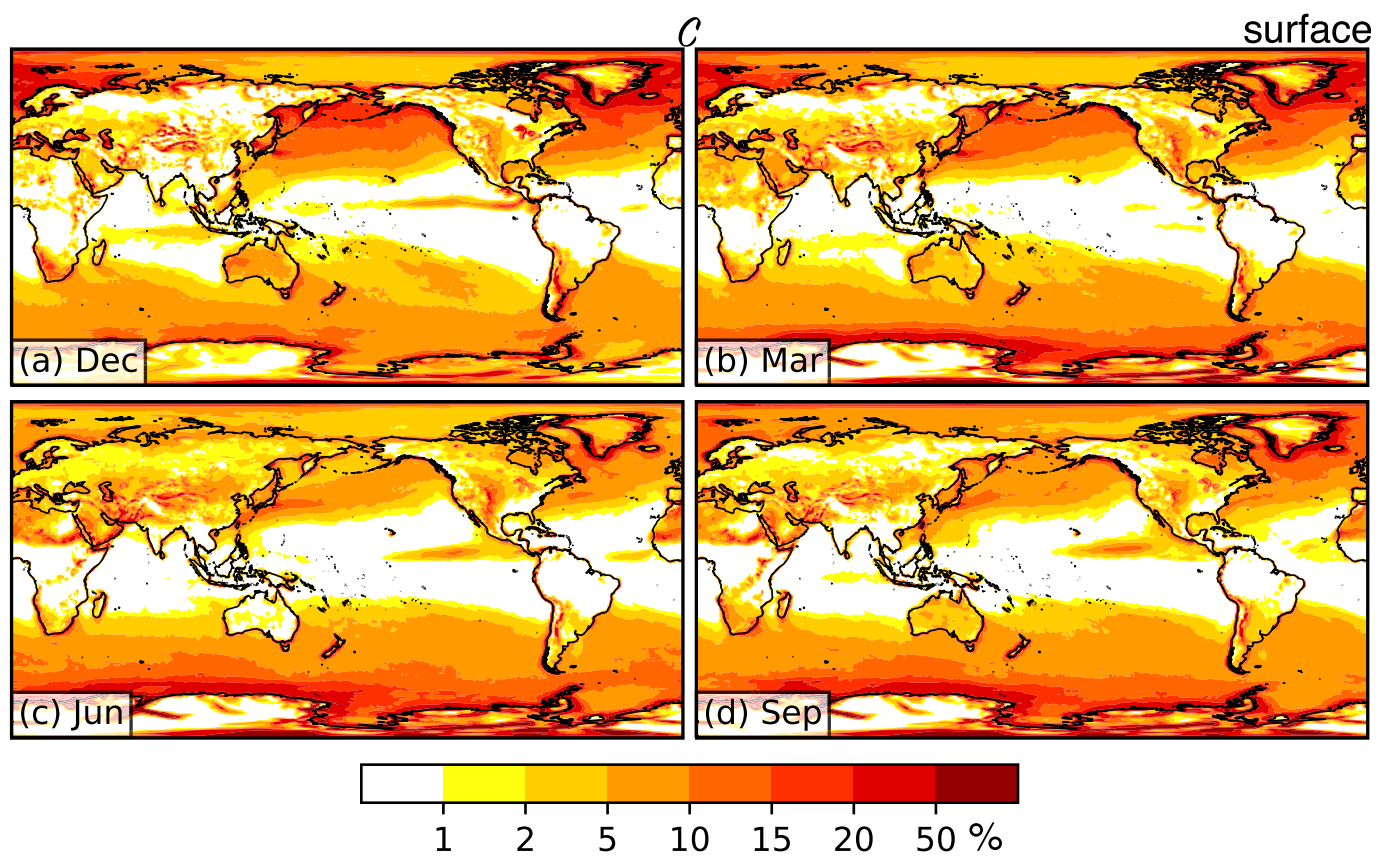

FIG. 23. Frequency of asymptotic contraction rate at the surface exceeding $0.275 \mathrm{~s}^{-1}$ (\%, colored according to scale) for (a) December, (b) March, (c) June, and (d) September.

For defining fronts, frontogenesis has the advantage of being both physically motivated, as it is a derived quantity that directly relates to the formation of fronts, and dynamically motivated through its links to the secondary circulation (section 2b; Thomas and Schultz 2019). The use of frontogenesis is also consistent with Douglas (1952, p. 9), who argued that convergence [i.e., one of the terms of Petterssen frontogenesis in (4)] was essential for a baroclinic zone to be considered a front, and with the definition of a front proposed by Sanders $(1999,2005)$, who argued that true fronts should possess both a temperature gradient and a wind shift.

Despite the absence of a thermodynamic quantity, the wind field has also been used to represent fronts. For example, Simmonds et al. (2012) used wind-based diagnostics to define fronts (or, more accurately, airstream boundaries in our terminology) and evaluated their results at both the surface and $850 \mathrm{hPa}$. Their wind-based results differed in some situations from those using a thermal-based quantity (e.g., Schemm et al. 2015), indicating that the choice of definition can exert a strong influence on the results. In the present article, we examined the asymptotic contraction rate, which is a quantitative measure of an airstream boundary. In some contexts, fronts and airstream boundaries may be similar or complementary. Our results show that the asymptotic contraction rate creates a climatology similar to that from frontal climatologies in many key locations around the world, except at the surface where maxima in frequency of occurrence appear that many would not recognize as fronts or airmass boundaries.

Generalizing further, both fronts and airstream boundaries may be viewed as airmass boundaries. Although the process that can form a front can happen within an air mass, fronts often form at the edges of air masses, hearkening back to the original definition of front proposed by the Bergen School (e.g., Bjerknes 1919): a boundary between two air masses with different source regions and histories (e.g., Schultz and Blumen 2015). As such, we should expect some overlap, albeit not perfect, between fronts and airstream boundaries.

\section{c. Algorithm to identify a front}

The last choice in defining a front is an algorithm to draw the line on the map corresponding to the front. Of the 12 climatologies of fronts in Table 2, only 6 involve the drawing of the front. Five identify regions on the map exceeding the threshold and mark that region as the frontal zone, as this study does. The twelfth one, Spensberger and Sprenger (2018), defines frontal volumes. Although no algorithm has been applied to draw front lines in this present study, the other six studies, as well as this one, produce viable climatologies of locations exceeding the thresholds. Specifically, the global distribution of fronts is still well represented in, for example, Figs. 3 and 11. Admittedly, small regions or short 
line segments that exceed the threshold and otherwise meet the criteria for a front may be identified. Locations next to mountains that exceed the threshold might be identified in this way as well, but other small segments do not appear to influence the climatology in a meaningful way (i.e., previous climatologies in the literature are similar whether or not lines were drawn). Also, climatologies capturing frontal zones (e.g., based on the gradient) may appear broader on maps than fronts capturing narrower regions (e.g., based on TFP). Consequently, we find no evidence that the method of identifying fronts (i.e., a line or a region) produces an inferior climatology.

\section{Summary}

Previous attempts to build a global climatology of fronts were limited by the lack of a unique definition of what constitutes a front and how the inability to define a front through the thermodynamic quantity, mathematical function, minimum threshold, and horizontal level leads to sensitivities in the resulting climatologies. Previous studies also failed to compare their choice of definition of a front to other possible choices, in order to understand the strengths and weaknesses of the various choices. For comparison, the most climatological fields that any previous study had calculated was two (i.e., Berry et al. 2011b; Simmonds et al. 2012; Schemm et al. 2015). To address these issues, we constructed a series of 17 monthly climatologies using the same dataset, the same time period, a consistent methodology and plotting scheme, and broken up by season or month instead of an annual average, allowing distinctions between these approaches to be revealed. By showing the monthly averages rather than annual or seasonal averages, we also avoid the tendency for the annual or seasonal averages to smooth the spatial fields, reducing the differences between the climatologies [cf. Fig. 8 in the present study and Fig. 7b in Thomas and Schultz (2019)].

The principal results from this study include the following:

1) Dramatic differences in the resulting spatial distributions and annual cycles of these 17 climatologies illustrate the importance of careful selection of an appropriate quantity, function, threshold, and level in determining climatologies of fronts, airstream boundaries, and airmass boundaries.

2) Minimum thresholds to constitute a front can be selected at any tolerance, but visual comparison to manually analyzed fronts suggests that a plausible threshold would be the top $10 \%$ of values.
3) Most climatologies (particularly those using $\theta$ ) reveal synoptic features such as the locations of midlatitude storm tracks, coastal fronts, subtropical moisture, and airmass boundaries. Such features are consistent with previously published manual and automated climatologies (Tables 1 and 2).

4) Seasonal variations in frequencies of fronts (particularly those using $\theta$ ) are typically larger over the continents, particularly in the Northern Hemisphere.

5) Thermodynamic quantities that involve moisture (i.e., $\theta_{e}$ ) shift the spatial distribution of fronts associated with the midlatitude storm tracks toward the tropics relative to thermodynamic quantities without moisture (i.e., $\theta$ ). More features at low latitudes are also present (e.g., around the subtropical anticyclones, South Atlantic and South Pacific convergence zones), indicating the increased importance of moisture toward the climatology.

6) The mathematical function TFP shifts the spatial distribution of fronts toward the tropics relative to the gradient or frontogenesis functions.

7) The climatology of $\operatorname{TFP}\left(\theta_{e}\right)$ results in most of the globe experiencing a frequency of fronts exceeding $4 \%$, much higher values and more spatial coverage than would be generally accepted relative to other quantities.

8) Maxima in the frequencies of $F(\theta)$ and $F\left(\theta_{e}\right)$ correspond closely to the known distribution of fronts without highlighting many moisture gradients or oceanic thermal gradients reflected in the atmosphere, suggesting that frontogenesis can be more effective for quantitatively discriminating fronts from nonfrontal baroclinic zones than the gradient or TFP.

9) A climatology of airstream boundaries, determined from asymptotic contraction rate, is largely similar to climatologies based on thermal quantities.

10) When averaged across the globe, fronts are stronger at the surface than at $850 \mathrm{hPa}$. The $10 \%$ most intense 850 -hPa fronts are more common over the oceans. However, the $10 \%$ most intense surface fronts are more common over land than over the oceans than the land. Therefore, surface-based thermodynamic quantities do not adequately capture fronts over the ocean, suggesting the necessity of looking aloft for fronts with larger thermal gradients. The addition of surface wind fields through frontogenesis or asymptotic contraction rate increases the frequency of surface fronts over the ocean.

In this study, we were interested in examining the effect that these choices in definitions of fronts, airmass 
boundaries, and airstream boundaries had on the climatologies resulting from these choices. As we argued in section 1, few previous studies have performed intercomparisons using different choices, with many that did an intercomparison confining it to cases only. Although we argue in Thomas and Schultz (2019) that approaches using $\theta_{e}$ are problematic for identifying fronts because of their dependence upon humidity and temperature, researchers will likely continue to use it. In this sense, we do not agree with Schemm et al. (2018, p. 160), who would revise their analysis of what they term "frontal markers" given an "ultimate front definition." Instead, we presented 17 climatologies for a suite of plausible frontal definitions (18 in the online supplemental material) and saw the effect of these choices, letting the user decide what is best for their purposes. Rather, given the availability of datasets for research that provide frontal segments (e.g., Sprenger et al. 2017), users of such data should be aware of the definition of a front used, how they are created, and the impact such choices have on the resulting research.

Acknowledgments. Funding for Thomas was provided by the U.K. Natural Environment Research Council through the Manchester-Liverpool Doctoral Training Programme Grant NE/L002469/1. Partial funding for Schultz was provided by the Natural Environment Research Council Grants NE/I026545/1 and NE/N003918/1 to the University of Manchester. We thank Callum Thompson for his assistance with this research, Eric Hoffman for his insights into his previous research, and Gareth Berry for discussions about his research. We thank the anonymous peer reviewers of Thomas and Schultz (2019) for raising questions that we could address in this present article, in particular the spatial structure of the difference fields between functions of $\theta_{e}$ and $\theta$ (Figs. 5 and 9) and frontolysis (Figs. 12 and 21). We thank the anonymous peer reviewers for this present article for their helpful comments.

\section{REFERENCES}

Arnup, S. J., and M. J. Reeder, 2007: The diurnal and seasonal variation of the northern Australian dryline. Mon. Wea. Rev., 135, 2995-3008, https://doi.org/10.1175/MWR3455.1.

Berry, G., M. J. Reeder, and C. Jakob, 2011a: A global climatology of atmospheric fronts. Geophys. Res. Lett., 38, L04809, https:// doi.org/10.1029/2010GL046451.

_ C. Jakob, and M. J. Reeder, 2011b: Recent global trends in atmospheric fronts. Geophys. Res. Lett., 38, L21812, https:// doi.org/10.1029/2011GL049481.

Bindon, H. H., 1940: Relation between equivalent potential temperature and wet-bulb potential temperature. Mon. Wea. Rev., 68, 243-245, https://doi.org/10.1175/1520-0493(1940)068<0243: RBEPTA $>2.0 . C O ; 2$.
Bjerknes, J., 1919: On the structure of moving cyclones. Geofys. Publ., 1 (2), 1-8.

Buban, M. S., C. L. Ziegler, E. N. Rasmussen, and Y. P. Richardson, 2007: The dryline on 22 May 2002 during IHOP: Ground-radar and in situ data analyses of the dryline and boundary layer evolution. Mon. Wea. Rev., 135, 2473-2505, https://doi.org/ 10.1175/MWR3453.1.

Burls, N. J., and C. J. C. Reason, 2006: Sea surface temperature fronts in the midlatitude South Atlantic revealed by using microwave satellite data. J. Geophys. Res., 111, C08001, https:// doi.org/10.1029/2005JC003133.

Carvalho, L. M., C. Jones, and B. Liebmann, 2004: The South Atlantic convergence zone: Intensity, form, persistence, and relationships with intraseasonal to interannual activity and extreme rainfall. J. Climate, 17, 88-108, https://doi.org/10.1175/ 1520-0442(2004)017<0088:TSACZI >2.0.CO;2.

Catto, J. L., C. Jakob, and N. Nicholls, 2013: A global evaluation of fronts and precipitation in the ACCESS model. Aust. Meteor. Ocean J., 63, 191-203, https://doi.org/10.22499/2.6301.012.

_ N. Nicholls, C. Jakob, and K. L. Shelton, 2014: Atmospheric fronts in current and future climates. Geophys. Res. Lett., 41, 7642-7650, https://doi.org/10.1002/2014GL061943.

Charles, A. N., J. R. Brown, A. Cottrill, K. L. Shelton, T. Nakaegawa, and Y. Kuleshov, 2014: Seasonal prediction of the South Pacific convergence zone in the austral wet season. J. Geophys. Res. Atmos., 119, 12 546-12 557, https://doi.org/ 10.1002/2014JD021756.

Cohen, R. A., and C. W. Kreitzberg, 1997: Airstream boundaries in numerical weather simulations. Mon. Wea. Rev., 125, 168-183, https://doi.org/10.1175/1520-0493(1997)125<0168:ABINWS > 2.0.CO;2.

- and D. M. Schultz, 2005: Contraction rate and its relationship to frontogenesis, the Lyapunov exponent, fluid trapping, and airstream boundaries. Mon. Wea. Rev., 133, 1353-1369, https:// doi.org/10.1175/MWR2922.1.

Dee, D. P., and Coauthors, 2011: The ERA-Interim reanalysis: Configuration and performance of the data assimilation system. Quart. J. Roy. Meteor. Soc., 137, 553-597, https://doi.org/ 10.1002/qj.828.

de la Torre, L., R. Nieto, M. Noguerol, J. A. Añel, and L. Gimeno, 2008: A climatology based on reanalysis of baroclinic developmental regions in the extratropical Northern Hemisphere. Ann. N. Y. Acad. Sci., 1146, 235-255, https://doi.org/ 10.1196/annals.1446.017.

Doswell, C. A., III, and D. M. Schultz, 2006: On the use of indices and parameters in forecasting severe storms. Electronic. J. Severe Storms Meteor., 1 (3), 1-14.

Douglas, C. K. M., 1952: The evolution of 20th-century forecasting in the British Isles. Quart. J. Roy. Meteor. Soc., 78, 1-21, https:// doi.org/10.1002/qj.49707833502.

Flocas, A. A., 1984: The annual and seasonal distribution of fronts over central-southern Europe and the Mediterranean. Int. J. Climatol., 4, 255-267, https://doi.org/10.1002/joc.3370040304.

Folland, C. K., J. A. Renwick, M. J. Salinger, and A. B. Mullan, 2002: Relative influences of the interdecadal Pacific oscillation and ENSO in the South Pacific convergence zone. Geophys. Res. Lett., 29, https://doi.org/10.1029/2001GL014201.

Garreaud, R., J. Rutllant, and H. Fuenzalida, 2002: Coastal lows along the subtropical west coast of South America: Mean structure and evolution. Mon. Wea. Rev., 130, 75-88, https:// doi.org/10.1175/1520-0493(2002)130<0075:CLATSW >2.0.CO;2.

Gold, E., 1935: Fronts and occlusions. Quart. J. Roy. Meteor. Soc., 61, 107-158, https://doi.org/10.1002/qj.49706125902. 
Hewson, T. D., 1998: Objective fronts. Meteor. Appl., 5, 37-65, https://doi.org/10.1017/S1350482798000553.

— , and H. A. Titley, 2010: Objective identification, typing and tracking of the complete life-cycles of cyclonic features at high spatial resolution. Meteor. Appl., 17, 355-381, https://doi.org/ 10.1002/met.204.

Hoffman, E. G., 2008: Surface potential temperature as an analysis and forecasting tool. Synoptic-Dynamic Meteorology and Weather Analysis and Forecasting: A Tribute to Fred Sanders, Meteor. Monogr., No. 55, Amer. Meteor. Soc., 163-181, https:// doi.org/10.1175/0065-9401-33.55.163.

Hope, P., and Coauthors, 2014: A comparison of automated methods of front recognition for climate studies: A case study in southwest Western Australia. Mon. Wea. Rev., 142, 343363, https://doi.org/10.1175/MWR-D-12-00252.1.

Hurd, W. E., 1929: Northers of the Gulf of Tehuantepec. Mon. Wea. Rev., 57, 192-194, https://doi.org/10.1175/1520-0493(1929) $57<192:$ NOTGOT $>2.0 . C O ; 2$.

Jenkner, J., M. Sprenger, I. Schwenk, C. Schwierz, S. Dierer, and D. Leuenberger, 2010: Detection and climatology of fronts in a high-resolution model reanalysis over the Alps. Meteor. Appl., 17, 1-18, https://doi.org/10.1002/met.142.

Keen, C. S., and W. A. Lyons, 1978: Lake/land breeze circulations on the western shore of Lake Michigan. J. Appl. Meteor., 17, 1843-1855, https://doi.org/10.1175/1520-0450(1978)017<1843: LBCOTW $>2.0 . \mathrm{CO} ; 2$.

Keyser, D., M. J. Reeder, and R. J. Reed, 1988: A generalization of Petterssen's frontogenesis function and its relation to the forcing of vertical motion. Mon. Wea. Rev., 116, 762-781, https:// doi.org/10.1175/1520-0493(1988)116<0762:AGOPFF>2.0.CO;2.

Laird, N. F., D. A. Kristovich, X. Liang, R. W. Arritt, and K. Labas, 2001: Lake Michigan lake breezes: Climatology, local forcing, and synoptic environment. J. Appl. Meteor., 40, 409-424, https://doi.org/10.1175/1520-0450(2001)040<0409:LMLBCL> 2.0.CO;2.

Lélé, M. I., and P. J. Lamb, 2010: Variability of the Intertropical Front (ITF) and rainfall over the West African Sudan-Sahel zone. J. Climate, 23, 3984-4004, https://doi.org/10.1175/ 2010JCLI3277.1.

McCann, D. W., and J. P. Whistler, 2001: Problems and solutions for drawing fronts objectively. Meteor. Appl., 8, 195-203, https://doi.org/10.1017/S1350482701002079.

Morgan, G. M., Jr., D. G. Brunkow, and R. C. Beebe, 1975: Climatology of surface fronts. Illinois State Water Survey Circular ISWS-7S-122, $46 \mathrm{pp}$.

Nicholson, S., 2018: The ITCZ and the seasonal cycle over equatorial Africa. Bull. Amer. Meteor. Soc., 99, 337-348, https://doi.org/10.1175/BAMS-D-16-0287.1.

Parmenter, F. C., 1970: A “Tehuantepecer." Mon. Wea. Rev., 98, 479, https://doi.org/10.1175/1520-0493(1970)098<0479:POTMAT> 2.3.CO;2

Petterssen, S., 1936: Contribution to the theory of frontogenesis. Geofys. Publ., 11 (6), 1-27.

- 1939: Frontogenesis and fronts in the Atlantic area. Proc. Sixth General Assembly Int. Union of Geodesy and Geophysics, Edinburgh, Scotland, IUGG, 1-22.

_ 1956: Weather Analysis and Forecasting. Vol. 1, Motion and Motion Systems, 2nd ed. McGraw-Hill, 428 pp.

Reed, R. J., and B. A. Kunkel, 1960: The Arctic circulation in summer. J. Meteor., 17, 489-506, https://doi.org/10.1175/15200469(1960)017<0489:TACIS > 2.0.CO;2.

Renard, R. J., and L. C. Clarke, 1965: Experiments in numerical objective frontal analysis. Mon. Wea. Rev., 93, 547-556,
https://doi.org/10.1175/1520-0493(1965)093<0547:EINOFA $>$ 2.3.CO;2.

Sanders, F., 1999: A proposed method of surface map analysis. Mon Wea. Rev., 127, 945-955, https://doi.org/10.1175/1520-0493(1999) 127<0945:APMOSM>2.0.CO;2.

, 2005: Real front or baroclinic trough? Wea. Forecasting, 20, 647-651, https://doi.org/10.1175/WAF846.1.

_ , and C. A. Doswell III, 1995: A case for detailed surface analysis. Bull. Amer. Meteor. Soc., 76, 505-522, https://doi.org/ 10.1175/1520-0477(1995)076<0505:ACFDSA > 2.0.CO;2.

_ , and E. G. Hoffman, 2002: A climatology of surface baroclinic zones. Wea. Forecasting, 17, 774-782, https://doi.org/10.1175/ 1520-0434(2002)017<0774:ACOSBZ>2.0.CO;2.

Santurette, P., and A. Joly, 2002: ANASYG/PRESYG, Météo-France's new graphical summary of the synoptic situation. Meteor. Appl., 9, 129-154, https://doi.org/10.1017/S1350482702002013.

Saucier, W. J., 1955: Principles of Meteorological Analysis. The University of Chicago Press, $438 \mathrm{pp}$.

Schemm, S., I. Rudeva, and I. Simmonds, 2015: Extratropical fronts in the lower troposphere-Global perspectives obtained from two automated methods. Quart. J. Roy. Meteor. Soc., 141, 1686-1698, https://doi.org/10.1002/qj.2471.

_- M. Sprenger, and H. Wernli, 2018: When during their life cycle are extratropical cyclones attended by fronts? Bull. Amer. Meteor. Soc., 99, 149-165, https://doi.org/10.1175/BAMS-D-16-0261.1.

Schneider, T., T. Bischoff, and G. H. Haug, 2014: Migrations and dynamics of the intertropical convergence zone. Nature, $\mathbf{5 1 3}$, 45-53, https://doi.org/10.1038/nature13636.

Schultz, D. M., 2009: Eloquent Science: A Practical Guide to Becoming a Better Writer, Speaker, and Atmospheric Scientist. Amer. Meteor. Soc., 440 pp.

_ 2015: Frontogenesis. Encyclopedia of Atmospheric Sciences, Vol. 5, 2nd ed. G. R. North, J. Pyle, and F. Zhang, Eds., Elsevier, 353-358.

- , and W. Blumen, 2015. Fronts. Encyclopedia of Atmospheric Sciences, Vol. 5, 2nd ed. G. R. North, J. Pyle, and F. Zhang, Eds., Elsevier, 337-343.

_ W. E. Bracken, L. F. Bosart, G. J. Hakim, M. A. Bedrick, M. J. Dickinson, and K. R. Tyle, 1997: The 1993 Superstorm cold surge: Frontal structure, gap flow, and tropical impact. Mon. Wea. Rev., 125, 5-39, https://doi.org/10.1175/1520-0493(1997) $125<0005$ :TSCSFS $>2.0$. CO;2; Corrigendum, 125, 662, https:// doi.org/10.1175/1520-0493-125.4.662.

,$- \ldots$, and - 1998: Planetary- and synoptic-scale signatures associated with Central American cold surges. Mon. Wea. Rev., 126, 5-27, https://doi.org/10.1175/1520-0493(1998)126<0005: PASSSA $>2.0 . \mathrm{CO} ; 2$.

Schumann, T. E. W., and M. P. van Rooy, 1951: Frequency of fronts in the Northern Hemisphere. Arch. Meteor. Geophys. Bioklim. A, 4, 87-97, https://doi.org/10.1007/BF02246795.

Serreze, M. C., A. H. Lynch, and M. P. Clark, 2001: The Arctic frontal zone as seen in the NCEP-NCAR reanalysis. $J$. Climate, 14, 1550-1567, https://doi.org/10.1175/1520-0442(2001) $014<1550$ :TAFZAS $>2.0 . \mathrm{CO} ; 2$.

Simmonds, I., K. Keay, and J. A. T. Bye, 2012: Identification and climatology of Southern Hemisphere mobile fronts in a modern reanalysis. J. Climate, 25, 1945-1962, https://doi.org/ 10.1175/JCLI-D-11-00100.1.

Solman, S. A., and I. Orlanski, 2010: Subpolar high anomaly preconditioning precipitation over South America. J. Atmos. Sci., 67, 1526-1542, https://doi.org/10.1175/2009JAS3309.1.

Spensberger, C., and M. Sprenger, 2018: Beyond cold and warm: An objective classification for maritime midlatitude fronts. 
Quart. J. Roy. Meteor. Soc., 144, 261-277, https://doi.org/ 10.1002/qj.3199.

Sprenger, M., and Coauthors, 2017: Global climatologies of Eulerian and Lagrangian flow features based on ERAInterim. Bull. Amer. Meteor. Soc., 98, 1739-1748, https:// doi.org/10.1175/BAMS-D-15-00299.1.

Steenburgh, W. J., D. M. Schultz, and B. A. Colle, 1998: The structure and evolution of gap outflow over the Gulf of Tehuantepec, Mexico. Mon. Wea. Rev., 126, 2673-2691, https:// doi.org/10.1175/1520-0493(1998)126<2673:TSAEOG > 2.0.CO;2.

Thomas, C. M., and D. M. Schultz, 2019: What are the best thermodynamic quantity and function to define a front in gridded model output? Bull. Amer. Meteor. Soc., https://doi.org/10.1175/ BAMS-D-18-0137.1, in press.

Thorpe, A. J., and S. A. Clough, 1991: Mesoscale dynamics of cold fronts: Structures described by dropsoundings in FRONTS 87. Quart. J. Roy. Meteor. Soc., 117, 903-941, https://doi.org/10.1002/ qj.49711750103.

Trasviña Castro, A., E. D. Barton, J. Brown, H. S. Velez, P. M. Kosro, and R. L. Smith, 1995: Offshore wind forcing in the Gulf of Tehuantepec, Mexico: The asymmetric circulation. J. Geophys. Res., 100, 20 649-20 663, https://doi.org/10.1029/ 95JC01283.
Utsumi, N., H. Kim, S. Seto, S. Kanae, and T. Oki, 2014: Climatological characteristics of fronts in the western North Pacific based on surface weather charts. J. Geophys. Res. Atmos., 119, 9400-9418, https://doi.org/10.1002/2014JD021734.

Vincent, D. G., 1994: The South Pacific convergence zone (SPCZ): A review. Mon. Wea. Rev., 122, 1949-1970, https://doi.org/ 10.1175/1520-0493(1994)122<1949:TSPCZA >2.0.CO;2.

Waliser, D. E., and C. Gautier, 1993: A satellite-derived climatology of the ITCZ. J. Climate, 6, 2162-2174, https://doi.org/ 10.1175/1520-0442(1993)006<2162:ASDCOT>2.0.CO;2.

Wendland, W. M., and R. A. Bryson, 1981: Northern Hemisphere airstream regions. Mon. Wea. Rev., 109, 255-270, https://doi.org/ 10.1175/1520-0493(1981)109<0255:NHAR > 2.0.CO;2.

— climatology. Mon. Wea. Rev., 114, 88-94, https://doi.org/10.1175/ 1520-0493(1986) $114<0088$ :SHAC $>2.0 . C O ; 2$.

Young, G. S., and J. M. Fritsch, 1989: A proposal for general conventions in analyses of mesoscale boundaries. Bull. Amer. Meteor. Soc., 70, 1412-1421, https://doi.org/10.1175/1520-0477(1989) $070<1412$ :APFGCI $>2.0 . \mathrm{CO} ; 2$

Žagar, N., G. Skok, and J. Tribbia, 2011: Climatology of the ITCZ derived from ERA Interim reanalyses. J. Geophys. Res., 116, D15103, https://doi.org/10.1029/2011JD015695. 